\title{
Interaction between sugar and abscisic acid signalling during early seedling development in Arabidopsis
}

\author{
Bas J. W. Dekkers · Jolanda A. M. J. Schuurmans • \\ Sjef C. M. Smeekens
}

Received: 17 November 2007 / Accepted: 2 February 2008/Published online: 17 February 2008

(C) The Author(s) 2008

\begin{abstract}
Sugars regulate important processes and affect the expression of many genes in plants. Characterization of Arabidopsis (Arabidopsis thaliana) mutants with altered sugar sensitivity revealed the function of abscisic acid (ABA) signalling in sugar responses. However, the exact interaction between sugar signalling and ABA is obscure. Therefore ABA deficient plants with constitutive ABI4 expression (aba2-1/35S::ABI4) were generated. Enhanced ABI4 expression did not rescue the glucose insensitive (gin) phenotype of aba2 seedlings indicating that other ABA regulated factors are essential as well. Interestingly, both glucose and ABA treatment of Arabidopsis seeds trigger a post-germination seedling developmental arrest. The glucose-arrested seedlings had a drought tolerant phenotype and showed glucose-induced expression of ABSCISIC ACID INSENSITIVE3 (ABI3), ABI5 and LATE EMBRYOGENESIS ABUNDANT (LEA) genes reminiscent of ABA signalling during early seedling development. $A B I 3$ is a key regulator of the ABA-induced arrest and it is shown here that $A B I 3$ functions in glucose signalling as well. Multiple abi3 alleles have a glucose insensitive (gin) phenotype comparable to that of other known gin mutants. Importantly, glucose-regulated gene expression is disturbed in the abi3 background. Moreover, abi3 was insensitive to
\end{abstract}

Bas J. W. Dekkers and Jolanda A. M. J. Schuurmans contributed equally to this paper.

B. J. W. Dekkers - J. A. M. J. Schuurmans · S. C. M. Smeekens Department of Molecular Plant Physiology, Utrecht University, Padualaan 8, 3584 CH Utrecht, The Netherlands

B. J. W. Dekkers $(\bowtie)$

De Ruiter Seeds, Leeuwenhoekweg 52, 2660 BB

Bergschenhoek, The Netherlands

e-mail: bas.dekkers@deruiterseeds.com sugars during germination and showed sugar insensitive (sis) and sucrose uncoupled (sun) phenotypes. Mutant analysis further identified the ABA response pathway genes ENHANCED RESPONSE TO ABAl (ERAl) and $A B I 2$ as intermediates in glucose signalling. Hence, three previously unidentified sugar signalling genes have been identified, showing that ABA and glucose signalling overlap to a larger extend than originally thought.

Keywords Abscisic acid - ABA insensitive . Glucose insensitive · Seedling development . Sugar signalling

$\begin{array}{ll}\text { Abbreviations } \\ \text { ABA } & \text { Abscisic acid } \\ \text { ABI } & \text { ABA insensitive } \\ \text { ApL } & \text { ADP-glucose pyrophosphorylase large subunit } \\ \text { ERA } & \text { Enhanced response to ABA } \\ \text { GIN } & \text { Glucose insensitive } \\ \text { HXK } & \text { Hexokinase } \\ \text { ISI } & \text { Impaired sucrose induction } \\ \text { LEA } & \text { Late embryogenesis abundant } \\ \text { PC } & \text { Plastocyanin } \\ \text { SIS } & \text { Sugar insensitive } \\ \text { SUN } & \text { Sucrose uncoupled }\end{array}$

\section{Introduction}

Photosynthesis provides plants with sugars that play a central role in the plant life cycle as energy sources, storage molecules, structural components or intermediates for the synthesis of other organic molecules. Next to these metabolic functions, sugars act as signalling molecules with 
hormone-like properties. Both hexoses and disaccharides are able to induce signalling via different pathways (Jang and Sheen 1997; Loreti et al. 2001; Rolland et al. 2006). In plants glucose has been shown to affect many processes, including germination, early seedling growth, flowering and senescence (Gibson 2000, 2005; Smeekens 2000; Rolland et al. 2006). Moreover, glucose feeding of Arabidopsis seedlings affected the expression of many genes as shown by micro array studies (Price et al. 2004; Villadsen and Smith 2004; Li et al. 2006). Sugar-induced signal transduction has been shown to control gene expression via diverse mechanisms that include transcription, translation, and modification of mRNA and protein stability (Rolland et al. 2006).

Genetic analysis showed that sugar signalling in plants is closely associated with plant hormone biosynthesis and signalling, in particular with that of abscisic acid (ABA, for review see Finkelstein and Gibson 2001; Gazzarini and McCourt 2001; León and Sheen 2003; Rook et al. 2006; Dekkers and Smeekens 2007). Four screens for sugar response mutants i.e. sucrose uncoupled (sun), impaired sucrose induction (isi), glucose insensitive (gin) and sugar insensitive (sis) identified ABA deficient mutants (i.e. aba2/isi4/ginl/sis4 and aba3/gin5) and ABA insensitive4 (abi4/sun6/isi3/gin6/sis5) as sugar insensitive (ArenasHuertero et al. 2000; Huijser et al. 2000; Laby et al. 2000; Rook et al. 2001). ABI4 encodes an AP2 domain containing transcription factor that binds a CE1-like element present in many $\mathrm{ABA}$ and sugar regulated promoters (Finkelstein et al. 1998; Niu et al. 2002; Acevedo-Hernandez et al. 2005). These observations linked sugar regulation to $\mathrm{ABA}$ signalling. However, there are many more examples of co-regulation of sugar and $\mathrm{ABA}$ in plants. The expression of many genes is co-regulated by sugar and ABA. A study of Li et al. (2006) showed that $14 \%$ of the ABA upregulated genes are induced in response to glucose as well, in total nearly 100 genes. These included genes in stress responses, carbohydrate and nitrogen metabolism and signal transduction. Another group of nearly 40 genes was repressed by both $\mathrm{ABA}$ and glucose. In addition the authors identified a group of genes that showed a synergistic upregulation when treated with both ABA and glucose, including the ApL3 (ADP pyrophosphorylase large subunit) gene, which is involved in starch biosynthesis. An earlier study showed that ABA was not able to induce the $A p L 3$ gene but that ABA in combination with sugar boosted transcription levels in comparison to sugar treatment alone (Rook et al. 2001). Interestingly, Akihiro et al. (2005) found a similar ABA/sugar interaction for the regulation of $A p L 3$ expression and starch biosynthesis in rice (Oryza sativa). There are many other examples of processes and genes that are regulated by sugar and ABA. E.g. the ABA, stress and ripening-induced
(ASR) protein in grape (Vitis vinifera) that binds to the sugar response boxes in the promoter of the monosaccharide transporter $V v H T 1$. ASR mRNA expression is responsive to sugar and is modulated by ABA (Cakir et al. 2003). Both sugar and ABA signals also regulate the maize (Zea mays) invertase gene, Ivr2 (Trouverie et al. 2004). Thus ABA/sugar interactions were reported for a multitude of processes and in different plant species indicating that these interactions are physiologically relevant. Therefore, a thorough understanding of these sugar and ABA interactions is of importance.

An important strategy for the isolation of sugar response mutants makes use of the effect of exogenous supplied sugars on early seedling development in Arabidopsis Although the use of high sugar concentrations ( $>300 \mathrm{mM}$ ) possibly are above the physiological range, it provided an efficient screening method for mutants (reviewed by Rognoni et al. 2007). Such elevated sugar concentrations arrest early seedling development, which is characterized by the absence of cotyledon greening and leaf formation. The difference in phenotype between arrested and non-arrested seedlings was exploited to isolate sugar insensitive mutants that showed proper seedling development on high glucose (gin) and sucrose (sis) media. In addition to the aforementioned role of ABA biosynthesis and signalling such sugar response mutants revealed a role for HEXOKINASE1 (HXK1/GIN2) and ethylene signalling in the GIN response pathway (Zhou et al. 1998; Gibson et al. 2001; Cheng et al. 2002; Moore et al. 2003). ABA deficiency caused by either mutations in $A B A 1, A B A 2$ or $A B A 3$ (Koornneef et al. 1998), resulted in a clear gin phenotype but analysis of $A B A$ insensitive mutants resulted in more ambiguous phenotypes. In addition to abi4, only abi5 and abi8 showed a sugar insensitive phenotype, while for abil-1, abi2-1 and abi3-1 no or only a weak phenotype was reported (Arenas-Huertero et al. 2000; Huijser et al. 2000; Laby et al. 2000; Brocard et al. 2002; Brocard-Gifford et al. 2004). Nevertheless, a role for $A B I 3$ in sugar signalling during early seedling development was hinted too by later studies. E.g. ABI3 over expression lines were sugar hypersensitive (Finkelstein et al. 2002; Zeng and Kermode 2004) and abi3 mutants were insensitive to glucose in combination with ABA (Nambara et al. 2002). This insensitivity appeared to be allele specific and the assay used was different from other sugar sensitivity assays. However, in a more recent report WT glucose sensitivity during early seedling development for the abi3 mutant was observed (Yuan and Wysocka-Diller 2006). Thus it is unclear how and to what extend sugar and ABA signalling overlap.

ABA by itself blocked post-germination early seedling development, in addition to the role of ABA in the glucoseinduced seedling arrest (Lopez-Molina et al. 2001). Similar 
to glucose-arrested seedlings, ABA-arrested seedlings lacked greening and leaf formation. The ABA-induced seedling arrest is dependent on $A B I 3$ and $A B I 5$ activity and both abi3 and abi5 mutant do not arrest early seedling growth in response to ABA (Lopez-Molina et al. 2002). This ABA sensitivity is confined to a limited time window after the start of germination (Lopez-Molina et al. 2001; Lopez-Molina et al. 2002) Adding ABA after this sensitive phase to seedlings no longer affects vegetative development. Similarly, the glucose-induced seedling arrest could only be triggered in a similar limited time frame after sowing (Gibson et al. 2001).

Here a study of the role of ABA biosynthesis and ABA signalling in sugar response pathways is presented. In particular this study was focussed on the glucose-induced early seedling developmental arrest (the GIN pathway). Analysis of transgenic ABA deficient lines with ectopic $A B I 4$ expression (aba2-1/35S::ABI4) suggested that additional ABA-controlled factors are necessary to arrest early seedling development in response to glucose. $A B I 3$ expression and protein stability are controlled by $\mathrm{ABA}$ and $A B I 3$ is a key component in the ABA mediated pathway that blocks early development (Lopez-Molina et al. 2002; Zhang et al. 2005). Therefore, we investigated the role of $A B I 3$ in the GIN pathway. ABI3 encodes a B3 domain transcription factor that contains four conserved domains, one acidic activation domain (A1) and three basic domains (B1, B2 and B3, Giraudat et al. 1992; Finkelstein et al. 2002). $A B I 3$ directs seed specific gene expression and is required for induction of desiccation tolerance and seed dormancy and represses genes related to seed germination (Ooms et al. 1993; Hoecker et al. 1995; Nambara et al. 2000; Suzuki et al. 2001; Finkelstein et al. 2002). Other functions for $A B I 3$ include regulation of flowering, resource allocation, lateral root growth in response to auxin and serve as a signal transduction component downstream of PHYB signalling in seeds (Robinson and Hill 1999; Suzuki et al. 2001; Brady et al. 2003; Mazzella et al. 2005). Here we show that multiple abi3 mutants display a gin phenotype. The glucose insensitive phenotype observed for abi3 mutants was comparable to that of other known gin mutants like abal, abi4 and abi5. Moreover, abi3 mutants showed a reduced expression level of glucoseregulated genes. In addition, physiological and molecular experiments led to the conclusion that the glucose-arrested seedlings mimic ABA-arrested seedlings. This was supported by the observations that two other ABA response mutants, i.e. eral and abi2-1, showed altered glucose responsiveness as well. The identification of $A B I 3$ and two other ABA response loci as components in GIN signalling suggests that glucose and $\mathrm{ABA}$ signalling share more components than originally anticipated.

\section{Material and methods}

\section{Plant material}

Arabidopsis plants were grown in a climate chamber at $22^{\circ} \mathrm{C}$ with $70 \%$ humidity and a $16 \mathrm{~h} / 8 \mathrm{~h}$ light/dark cycle (Sylvania GRO-LUX fluorescent lamps; Technische Unie, Utrecht) for seed production. WT and mutant seeds that were compared in all experiments presented were produced together and stored under identical conditions. Seeds were dry-stored in paper bags at room temperature for at least a month before use in our experiments. The transgenic aba21/35S::ABI4 lines were constructed as follows. ABI4 cDNA sequence was PCR amplified and cloned in pDONR vector and sequenced. Using Gateway cloning ABI4 was cloned behind the Cauliflower Mosaic Virus 35S promoter in the pGD625 vector. The pGD625 vector containing 35S::ABI4 was introduced in Agrobacterium which were used to transform aba2-1 plants by the floral dip method (Clough and Bent 1998).

\section{Germination assays}

All germination assays were performed on 0.5 MS: halfstrength Murashige and Skoog medium (pH 5.8), including vitamins, solidified with $0.8 \%$ plant agar (Duchefa, Haarlem, The Netherlands). Before plating, seeds were surface-sterilized in $20 \%$ (v/v) commercial bleach (Glorix) for 15-20 min and rinsed four to five times with sterile water. After a three days stratification period at $4^{\circ} \mathrm{C}$ in the dark, plates (with or without sugars present as indicated) were incubated in the growth chamber $\left(22^{\circ} \mathrm{C}\right.$ and $16 \mathrm{~h} / 8 \mathrm{~h}$ light/dark cycle). To investigate the effect of stratification on sugar-free (0.5 MS) media seeds were transferred to sugar media after this stratification period. Control experiments showed that transferring of seeds did not affect seed germination. Germination defined as radicle emergence from the seed coat, was scored daily for 3-8 days. Experiments were performed in duplo, each plate containing 50-100 seeds, and every experiment was repeated one to three times.

\section{Sugar response assays}

For gin assay experiments seeds were sterilized, sown on $0.5 \mathrm{MS}$ media and stratified for three days at $4^{\circ} \mathrm{C}$ in the dark. Hereafter seeds were collected and sown on 0.5 MS media supplemented with $1 \%$ sucrose (control) or on control media with the indicated amount of sugar unless otherwise indicated. Different seed batches show slightly different responses and therefore both $7 \%$ and $8 \%$ glucose 
media were used. Plates were incubated in the growth chamber $\left(22^{\circ} \mathrm{C}\right.$ and $16 \mathrm{~h} / 8 \mathrm{~h}$ light/dark cycle) for up to two weeks. Seedlings were scored gin when green cotyledons emerged. To determine the isi phenotype of WT Col, aba21, L6 and L10 the seeds were stratified first for three days on sugar-free 0.5 MS media. After stratification the seeds were sown on $100 \mathrm{mM}$ sucrose media. After four days plant material was harvested and $A p L 3$ expression levels determined. For the sun phenotype analysis seeds were sterilized, sown on 0.5 MS and stratified for three days at $4{ }^{\circ} \mathrm{C}$ in darkness. After stratification seeds were transferred to plates containing $0.5 \mathrm{MS}$ or $0.5 \mathrm{MS}$ with the indicated amount of sugar. Seeds were light-treated for at least one hour before they were incubated in the dark (wrapped in three layers of aluminium foil) at $22^{\circ} \mathrm{C}$. After two days plant material was harvested for $P C$ expression analysis by qRT-PCR.

\section{Gene expression analysis}

WT Ler-0, abi3-1 and abi3-5 seeds were stratified for three days and germinated on $0.5 \mathrm{MS}$ media. Seed batches were germinated to approximately $70 \% \quad(t=0)$ before the start of the different treatments. At this stage all WT seedlings were developmentally arrested in response to elevated glucose concentrations and $\mathrm{ABA}$ treatment. For RNA isolation and qRT-PCR analysis plant material was ground using mortar and pestle in liquid nitrogen and additionally bead-beaten in a mikro-dismembrator S (B. Braun Biotech International, Germany). RNA was isolated according to Schuurmans et al. (2003). Additionally, RNA was purified using RNeasy columns (Qiagen USA, Valencia, CA). RNA samples were DNase treated, checked for the absence of DNA by PCR and used for cDNA synthesis and qRT-PCR analysis as described before by van Dijken et al. (2004). For expression analysis by qRT-PCR either a $5^{\prime}$ FAM $/ 3^{\prime}$ TAMRA labelled probe (with TaqMan ${ }^{\circledR} 2 \times$ Universal PCR Master Mix, Applied Biosystems, Foster City, CA) or SYBR ${ }^{\circledR}$ Green technology (Power SYBR ${ }^{\circledR}$ Green PCR Master Mix, Applied Biosystems, Foster City, CA) was used. Relative quantitation of gene expression is based on the comparative $\mathrm{C}_{\mathrm{T}}$ method (User Bulletin No. 2: $\mathrm{ABI}$ PRISM 7700 Sequence Detection System, 1997) using the AtACTIN2 (ACT2) as reference gene. The EM1 primers were obtained for the CATMA database (http://www. catma.org, EMI forward primer ID: 3a44750.5, EMI reverse primer ID: 3a44750.3). The sequences of primers and probes that were used for gene expression analysis are listed in Table 1. The qRT-PCRs were run on a ABI-prism 7700 Sequence Detection System (Applied Biosystems, Foster City, CA).

\section{Results}

Transgenic ABA deficient lines with constitutive expression of $A B I 4$ are glucose insensitive

Screens for sugar insensitive mutants revealed the importance of $\mathrm{ABA}$ and $\mathrm{ABA}$ signal transduction, in particular ABI4 (Arenas-Huertero et al. 2000; Huijser et al. 2000; Laby et al. 2000; Rook et al. 2001). To study the interaction between ABA biosynthesis and ABI4 in sugar signalling we generated transgenic lines with constitutive $A B I 4$ expression driven by a CaMV $35 \mathrm{~S}$ promoter in an ABA deficient (aba2-1) background. ABI4 expression in these transgenic aba2- 1 plants is independent from plant sugar status. Two lines homozygous for the $35 \mathrm{~S}:: A B I 4$ construct were selected, i.e. lines L6 and L10. Both lines germinated normally but showed a stunted growth phenotype (Fig. 1a) similar to what has been reported previously for severe ABI4 overexpression lines (Söderman et al. 2000). Expression analysis on control media showed that $A B I 4$ expression is high in L6 and L10 and exceeded glucose-induced $A B I 4$ expression in developmentally arrested WT Col seedlings by approximately 5-8 fold (Fig. 1b).

The gin phenotype of Col, aba2-1, L6 and L10 was tested by growing the lines for two weeks on control, $8 \%$ sorbitol and $8 \%$ glucose media. All lines showed greening on control (con) and sorbitol (sorb, osmotic control) media as expected (Fig. 1c). On glucose the Col seedlings showed an arrested phenotype whereas aba2-1 showed a gin phenotype as reported before (Fig. 1c, León and Sheen 2003). Also ABI4 expression levels in glucose-arrested Col seedlings were enhanced whereas in aba2-1 ABI4 expression was very low. The L6 and L10 aba2-1/35S::ABI4 lines have very high $A B I 4$ levels but, importantly, display a gin phenotype (Fig. 1c). The gin phenotype of aba2-1 and the transgenic lines could be reverted to WT by the addition of $100 \mathrm{nM}$ ABA as was reported before for $a b a$ mutants (Fig. 1c, Arenas-Huertero et al. 2000). Thus, in an ABA deficient background $A B I 4$ overexpression does not restore wild type sensitivity to glucose.

Sucrose feeding induces $A p L 3$ gene expression in Arabidopsis seedlings. This sugar regulation of the $A p L 3$ promoter has been used as basis for a screen for sugar response mutants. Rook et al. (2001) reported on isi sugar response mutants that were unable to fully activate $A p L 3$ expression in response to sucrose. The identification of aba2/isi4 and abi4/isi3 as mutants with an impaired sucrose induction phenotype revealed a role for $\mathrm{ABA}$ biosynthesis and signalling in control of $A p L 3$ expression (Rook et al. 2001). To study the sugar-induced $A p L 3$ expression in WT Col, aba2-1, L6 and L10 stratified seeds were sown on $100 \mathrm{mM}$ sucrose media. After four days 
Table 1 Primers and probes used for gene expression analysis

\begin{tabular}{llll}
\hline Gene & Forward primer & Reverse primer & Probe \\
\hline ACT2 & gctgagagattcagatgccca & atgggagctgctggaatccac & agtcttgttccagccetcgtttgtgc \\
ABI3 & cacagccagagttccttccttt & tgtggcatgggaccagact & cttgaatctccaccgtcatggccac \\
$A B I 4$ & cggtgggttcgagtctatcaa & cggatccagacccatagaaca & acctcatccaccgccgttggttga \\
$A B I 5$ & ggaggtggcgttgggttt & gggcttaacggtccaacca & tcccatttgctgtccacccgct \\
$E M 1$ & agatgggacacaaaggaggag & tgttggtgaactttgactcatcg & \\
$E M 6$ & ggtacgggaggcaaagctt & ttgcgtcccatctgctgata & cccaagaaacatccgtgtgagattaccg \\
$R A B 18$ & gagcaactccacaaggaaag & gtagccaccagcatcatatc & aaacgatcgaagctgctgttgccact \\
$A p L 3$ & cgagaagtgccggattgtaaa & ggaacgttggatgctgcatt & catggccatcgcatttcca \\
$P C$ & tcttgaaggatttcggtgtca & &
\end{tabular}

plant material was harvested and ApL3 expression levels determined. Sucrose feeding resulted in an approximate six fold induction of ApL3 in Col seedlings (Fig. 1d). The induction of ApL3 is $25 \%$ lower in the aba2-1 seedlings, which is in agreement with the isi phenotype of aba2/isi4 (Rook et al. 2001). In the L6 and L10 aba2-1/35S::ABI4 lines the $A p L 3$ expression level on sugar-free control media already exceeds that of sugar-treated WT seedlings. Sugar feeding of L6 and L10 seedlings further boosted ApL3 expression 7-9 fold higher than sugar-treated WT seedlings (Fig. 1d).

Glucose and ABA trigger a similar developmental early seedling arrest

High sugar concentrations arrest early seedling development in Arabidopsis. After germination vegetative seedling growth is blocked, characterized by the absence of cotyledon greening and leaf formation. Equimolar concentrations of an osmotic control did not block development in this early seedling stage (Fig. 2a; Zhou et al. 1998; Laby et al. 2000; Rognoni et al. 2007). Previously, Lopez-Molina et al. (2001) showed that treatment with ABA arrested this post-germination switch from embryonic to vegetative growth as well. ABA-arrested seedlings showed neither greening nor leaf formation similar to glucose-arrested seedlings (Fig. 2a). In comparison to ABA-arrested seedlings, glucose-arrested seedlings were larger due to the longer hypocotyl and larger cotyledons (Fig. 2b). Moreover, significant root growth was observed in glucose-arrested seedlings, which is absent in ABAarrested seedlings (Fig. 2a, b). Further, in glucose-arrested seedlings often a pink colouration was observed, indicative for anthocyanin accumulation that was absent in ABAarrested seedlings (Fig. 2a, b).

ABA-arrested seedlings possess an enhanced resistance to drought stress compared to non-arrested seedlings (Lopez-Molina et al. 2001). A comparison was made between the drought resistance phenotype of glucose- and ABA-arrested seedlings. Control (non-arrested) seedlings did not survive a drought treatment of $2.5 \mathrm{~h}$ (Fig. 2c). ABA-treated seedlings showed a near $100 \%$ survival rate after $6 \mathrm{~h}$ of drought, the longest treatment tested in our experiments. Glucose-arrested seedlings showed an intermediate drought resistance. After $2.5 \mathrm{~h}$ of drought stress, glucose-treated seedlings showed a nearly $90 \%$ survival rate and after $6 \mathrm{~h}$ of drought the survival rate was $50 \%$ compared to $0 \%$ survival observed for control seedlings. Thus, a clear drought resistant phenotype was observed for glucose-arrested seedlings.

The ABA-induced early seedling developmental arrest depends on functional $A B I 3$ and $A B I 5$ genes. abi3 and abi5 mutants did not block early seedling development in response to ABA. Moreover, WT seedlings exposed to ABA showed strongly enhanced ABI3 and ABI5 protein levels (Lopez-Molina et al. 2001, 2002). Both genes encode transcriptional regulators important for seed development and LEA gene expression (Koornneef and Karssen 1994; Parcy et al. 1994, Finkelstein and Lynch 2000; Carles et al. 2002). Lopez-Molina et al. (2002) showed that during the early seedling developmental arrest several LEA genes were re-induced as well. This re-induction of seed transcriptional regulators and $L E A$ gene expression suggested that a late embryogenesis program is re-initiated by ABA treatment, inducing a drought tolerant phenotype in such arrested seedlings (LopezMolina et al. 2002). It was investigated whether the same transcriptional regulators and $L E A$ genes were expressed by glucose signalling during early seedling development. A role for $A B I 5$ has been proposed in GIN signalling and $A B I 5$ expression is sugar responsive (Arenas-Huertero et al. 2000; Laby et al. 2000; Brocard et al. 2002; Arroyo et al. 2003). $A B I 5$ expression thus is a good positive control in this experiment. Gene expression upon glucose feeding was studied by germinating seeds on control medium until the batch reached $70 \%$ germination (time 
(A)

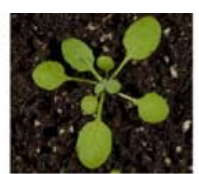

Col

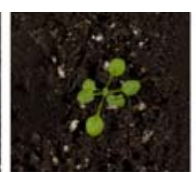

aba2-1

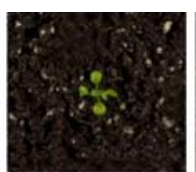

L6

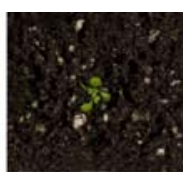

L10

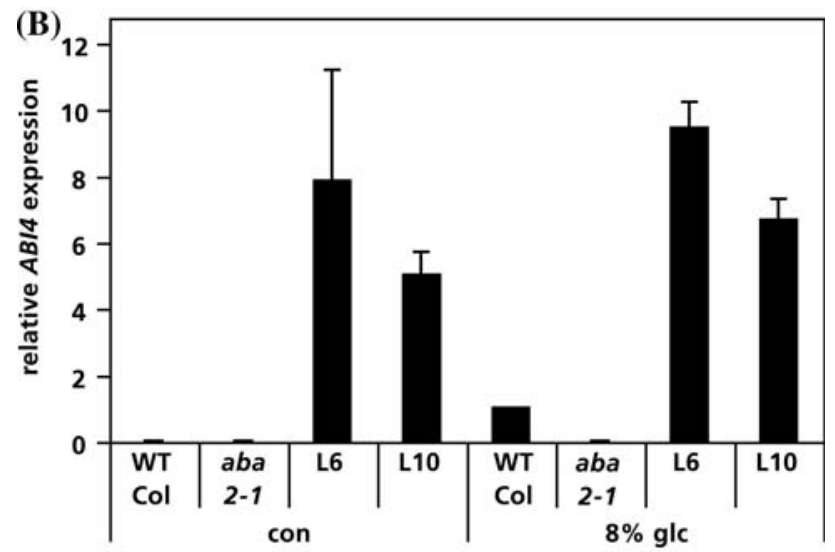

(C)

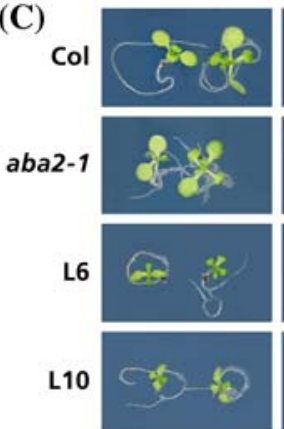

con
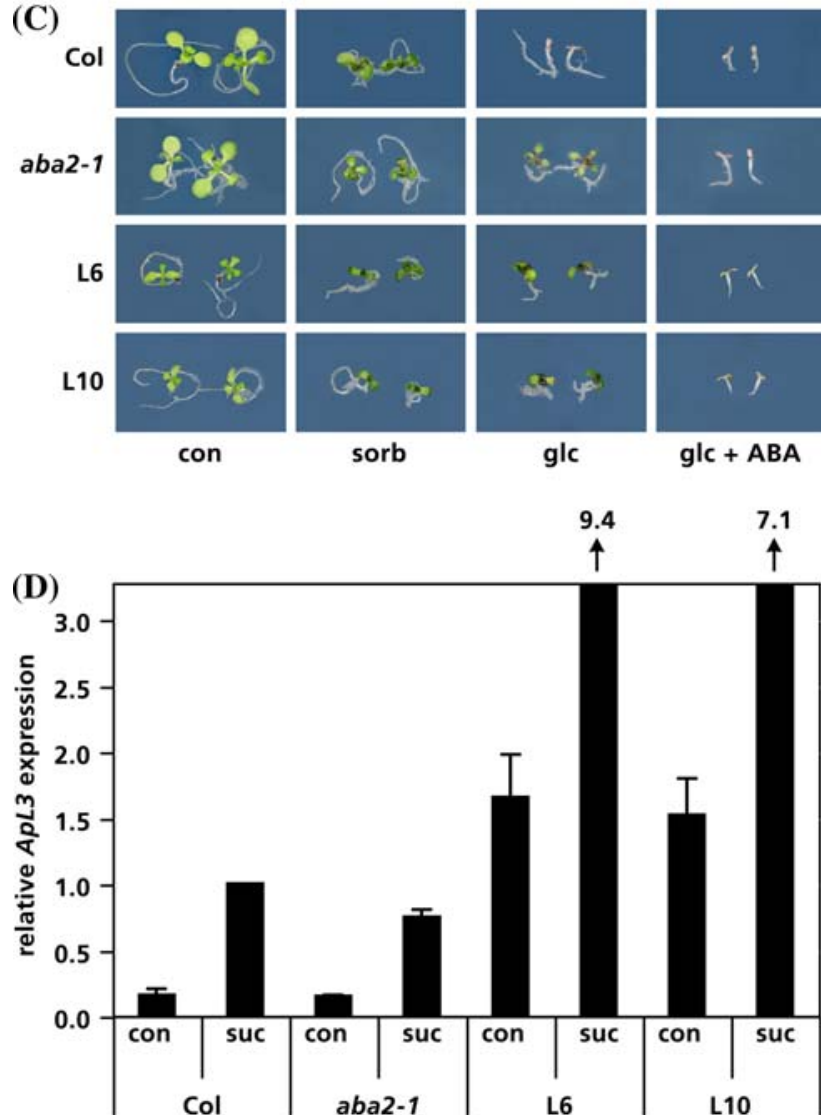

point zero, $t=0$ ). At this time point a sample was collected for RNA isolation while the rest of the seeds were transferred to control, sorbitol, glucose or ABA containing media for an additional $24 \mathrm{~h}$. After $24 \mathrm{~h}$ samples were collected for gene expression analysis. Using quantitative RT-PCR (qRT-PCR), the expression of $A B I 3, A B I 5$, $A t E M 1, A t E M 6$ and $R A B 18$ was studied in response to the
4Fig. 1 Analysis of transgenic ABA deficient lines with constitutive $A B I 4$ expression. Plant phenotypes of WT Col, aba2-1, and two transgenic lines with constitutive ABI4 expression in aba2-1 (L6 and L10) after 2,5 weeks of growth on soil (a). ABI4 expression was detected by qRT-PCR in Col, aba2-1, L6 and L10 seedlings grown for two weeks on control or $8 \%$ glucose media. Values are averages of two experiments $\pm \mathrm{SD}$ (b). Seedling phenotypes after two weeks of growth on control, $8 \%$ sorbitol (sorb), $8 \%$ glucose (glc) or $8 \%$ glucose $+0,1 \mu \mathrm{M}$ ABA (glc $+\mathrm{ABA})$. Similar results were obtained in three experiments (c). ApL3 expression was detected by qRT-PCR in Col, aba2-1, L6 and L10 seedlings grown for four days on control half-strength MS (con) or half-strength MS $+100 \mathrm{mM}$ sucrose (suc) media. Values are averages of three experiments \pm SD (d)

different treatments. Gene expression was studied in three independent experiments. In each experiment the gene expression level at $t=0$ was set to one (Table 2). Some variation in gene expression levels between the three experiments was observed, likely due to the fact that for each experiment independently generated seed batches were used. Generally, continued growth on control media after $\mathrm{t}=0$ resulted in a decreased expression of all five genes (Table 2). In contrast, treatments with sorbitol, glucose and ABA enhanced the expression of all genes studied, except for the sorbitol treatment in the second experiment. In this particular experiment gene expression decreased on sorbitol, however, this decrease was less pronounced compared to the control treatment. ABA treatment resulted in the re-induction of $A B I 3, A B I 5$ and the $L E A$ genes, which is in line with results reported by Lopez-Molina et al. (2002). Also glucose exposure significantly induced the expression levels of all five genes although the expression levels are in general somewhat lower than in response to $\mathrm{ABA}$. Thus $A B I 3$ is upregulated by glucose as well, which indicated a possible role for $A B I 3$ in glucose responsiveness. The observation that the expression levels of the genes studied are in general lower after sorbitol treatment compared to glucose treatment indicates that the glucose-induced expression is not an osmotic response.

Expression studies using seedlings grown for five days on control, sorbitol $(7 \%)$ or glucose $(7 \%)$ media confirmed the induction of these genes (Fig. 3). In five days old glucose-arrested seedlings enhanced expression levels were detected for $A B I 3$ and $A B I 5$ as well as the LEA genes $A t E M 1$, AtEM6 and RAB18. The induction of these genes by sorbitol was roughly five fold lower (Fig. 3). After $72 \mathrm{~h}$ of growth on ABA-free media, seedlings lose the capacity to re-induce $A B I 3, A B I 5$ and $L E A$ expression and to arrest early seedling development in response to ABA (LopezMolina et al. 2001, 2002). To study whether the induction by glucose is restricted to a similar time frame seeds were germinated and grown for three days on half-strength MS and subsequently switched for two additional days to elevated sorbitol and glucose media. The re-induction by 


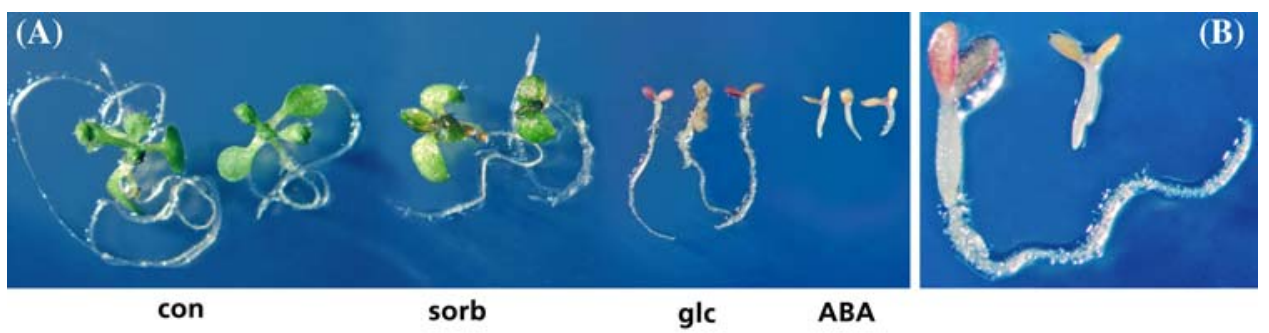

(C)

\begin{tabular}{|c|c|c|c|c|c|c|}
\hline \multirow[b]{3}{*}{ drying time (h) } & & \multicolumn{5}{|c|}{ seedling survival (in \%) } \\
\hline & \multicolumn{3}{|c|}{ Exp. 1 (Ws) } & \multicolumn{3}{|c|}{ Exp. 2 (Ler-0) } \\
\hline & con & ABA & glc & con & ABA & glc \\
\hline 0 & 100 & 100 & 100 & 100 & 100 & 100 \\
\hline 1 & 27 & 100 & 97 & 100 & 100 & 89 \\
\hline 2,5 & 0 & 100 & 87 & 0 & 100 & 85 \\
\hline 6 & 0 & 100 & 63 & 0 & 91 & 45 \\
\hline
\end{tabular}

Fig. 2 Glucose and ABA signalling arrest early seedling development and induce a drought tolerant phenotype. Ler-0 seedling phenotypes are shown after growth for twelve days on control (con, half-strength MS $+1 \%$ sucrose), or on con medium supplemented with either $7 \%$ sorbitol (sorb), 7\% glucose (glc) or $10 \mu \mathrm{M}$ ABA (ABA) (a). A close-up image of a glc-arrested seedling (left) and an ABA-arrested seedling (right) is shown (b). Developmentally arrested

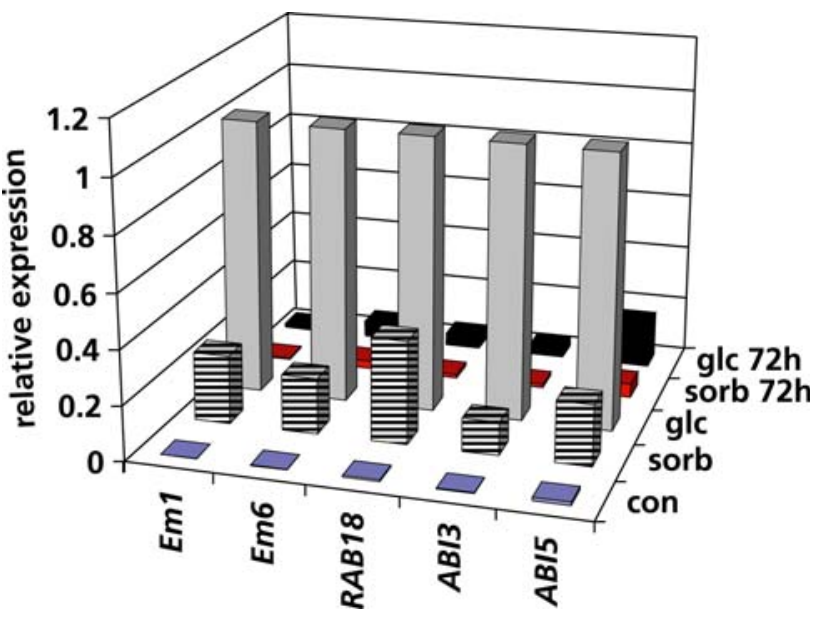

Fig. 3 The glucose-regulated expression of $A B I 3, A B I 5$ and $L E A$ genes is restricted to a limited time frame after the start of germination. The expression of EM1, EM6, RAB18, ABI3 and $A B I 5$ genes was quantified by qRT-PCR after germination and growth for five days on different media. Ler-0 seeds were plated for five days on control media (con, half-strength MS $+1 \%$ sucrose), or on con medium supplemented with either $7 \%$ sorbitol (sorb) or $7 \%$ glucose (glc). The values are an average of three experiments and in each experiment the expression on glc was set to one. It was investigated whether this gene expression regulation is limited to a small time window after the start of germination as has been shown for ABA regulation (Lopez-Molina et al. 2002). Therefore seeds were germinated on con media for three days and thereafter switched to either sorb (sorb $72 \mathrm{~h}$ ) or glc media (glc $72 \mathrm{~h}$ )

glucose of $A B I 3, A B I 5, E M 1, E M 6$ and $R A B 18$ was largely lost (Fig. 3, glc $72 \mathrm{~h}$ ). The weaker induction by sorbitol is essentially lost after three days (Fig. 3, sorb 72 h). Thus, seedlings have a drought tolerant phenotype. Seeds were grown on control (con) or on con media containing either $10 \mu \mathrm{M}$ ABA (ABA) or $7 \%$ glucose (glc) for nine days. At day nine the seedlings were subjected to a drought treatment as indicated (c). Hereafter seedlings were allowed to recover on control media for five days after which survival was scored. The survival percentage following drought treatment is presented (c)

the glucose-response that induced $A B I 3, A B I 5$ and $L E A$ expression is confined to a similar time frame as observed for ABA. This is in agreement with the finding that glucose regulation of $A B I 4$ and $A B I 5$ expression was dependent on developmental stage (Arroyo et al. 2003) and that sugar arrests early seedling development only in a small 2-3 day time frame after sowing (Gibson et al. 2001).

In conclusion, the glucose-induced block of early seedling development mimics the ABA-induced arrest of vegetative development in young seedlings. Both glucoseand ABA-arrested seedlings have a drought resistant phenotype and show enhanced expression levels of seed expressed genes. The observation that $A B I 4$ overexpression is unable to restore WT glucose sensitivity in the $a b a 2-1$ mutant shows that WT ABA biosynthesis is essential for the GIN response. Apparently, next to ABI4 additional factors which are under control of ABA are important for GIN signalling. Two candidates are $A B I 3$ and $A B I 5$. Both play a role in the ABA-induced early seedling developmental arrest and gene expression and protein stability of both transcription factors is affected by ABA (Lopez-Molina et al. 2001; Lopez-Molina et al. 2002; Lopez-Molina et al. 2003; Zhang et al. 2005; this study). A role for $A B I 5$ in glucose signalling has been established; abi5-1 has a gin phenotype (although somewhat weaker compared to abi4) and $A B I 5$ expression is regulated by sugar (Arenas-Huertero et al. 2000; Laby et al. 2000; Brocard et al. 2002; Arroyo et al. 2003; this study see Table 2). However, a role for $A B I 3$ is controversial (for review Finkelstein and Gibson 2001; Leon and Sheen 2003; Gibson 2004; Rognoni 
et al. 2007). Since $A B I 3$ is important for the ABA-induced developmental arrest and is induced by glucose, our hypothesis is that $A B I 3$ is involved in GIN signalling as well. Therefore, the gin phenotype and glucose-regulated gene expression were studied in abi3 mutants.

abi3 mutants are glucose insensitive

The glucose insensitive phenotype of WT Ler-0 and the abi3 mutant was investigated by plating seeds of both genotypes on media with elevated glucose concentrations (6-8\% glucose). Initially, two abi3 mutant alleles were tested, i.e. the weak abi3-1 allele (producing normal, drought tolerant seeds) and the strong abi3-5 allele (producing green, drought intolerant seeds, Ooms et al. 1993). As expected WT Ler-0 early seedling development was arrested in response to high glucose concentrations. In contrast, approximately 60-100\% (differed between experiments) of both abi3-1 and abi3-5 seedlings showed greening on high glucose media, suggesting that abi3 is a gin mutant, (Fig. 4a). All genotypes showed greening on control and osmotic control media (Fig. 4a, control and 7\% sorbitol, respectively). The gin phenotype was observed for abi3 mutants in several experiments using independently grown and harvested seed batches (data not shown). Next, the strength of the gin phenotype of abi3-1 was assessed in comparison to that of the ABA deficient mutant abal-1, which is in the Ler-0 background as well. The abal-1 mutant, like other ABA deficient mutants tested, was shown to possess a gin phenotype (Arenas-Huertero et al. 2000; Huijser et al. 2000; Laby et al. 2000). A similar percentage of seedling greening was observed for abal-1 and abi3-1 when grown on glucose media (Fig. 4b) suggesting that both mutants possess a comparable gin phenotype.

Six additional mutant alleles (abi3-8, abi3-9, abi3-10, abi3-11, abi3-12, and abi3-13) were obtained (a kind gift of Dr. E. Nambara) and tested for their gin phenotype. These abi3 mutants were tested along with two known gin mutants, abi4-3 and abi5-7 in the gin assay. All these mutants were retrieved from a screen for mutants insensitive to the unnatural (-)-ABA (Nambara et al. 2002). The ABA insensitivity of the mutants was tested by plating the mutants on half-strength MS media containing $1 \%$ sucrose $+10 \mu \mathrm{M}$ ABA. The ABA insensitivity observed was in agreement with that reported by Nambara et al. (2002) (see Table 3). The abi3-8, abi3-9, abi3-10, abi4-3 and abi5-7 mutants had a strong ABA insensitivity, the abi3-12 and abi3-13 showed a weaker phenotype. We did observe $40 \%$ greening for abi3-13 on ABA media while originally no $a b i$ phenotype was observed for this allele (Nambara et al. 2002). These mutants were isolated on $(-)$-ABA and the (-)-ABA insensitivity does not
(A)
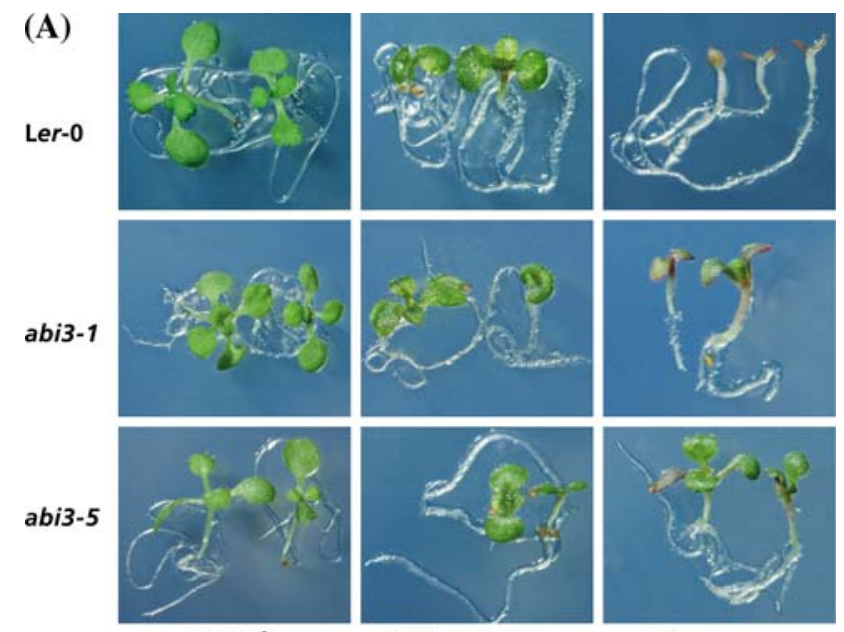

$7 \%$ sorbitol
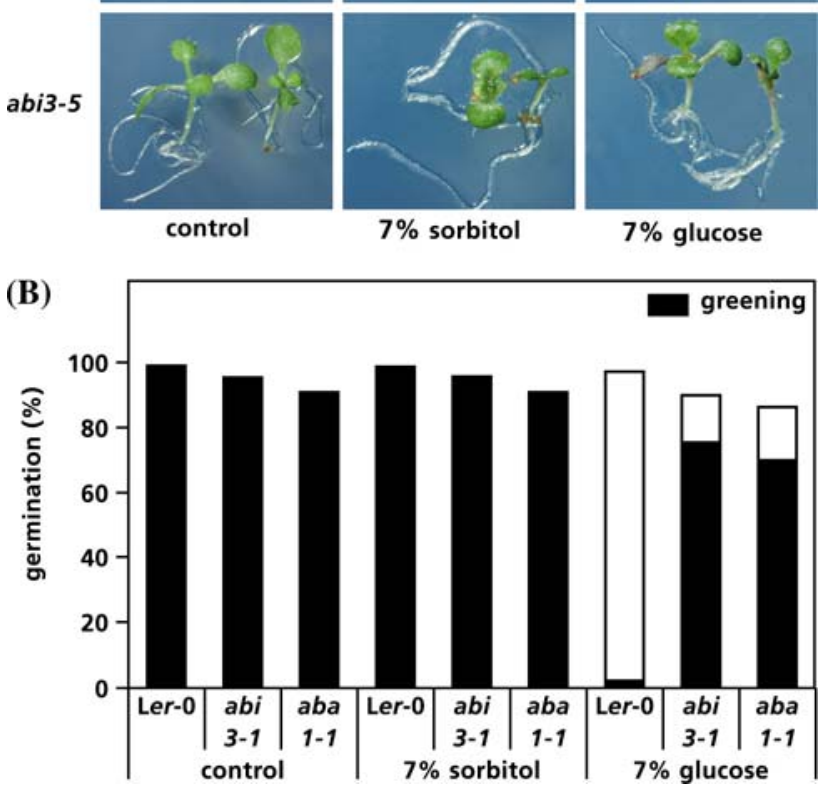

Fig. 4 abi3 mutants have a gin phenotype. Representative Ler-0, abi3-1 and abi3-5 seedlings are shown that were grown for 12 days on control media (half-strength $\mathrm{MS}+1 \%$ sucrose), or on control medium supplemented with either $7 \%$ sorbitol or $7 \%$ glucose (a). The gin phenotype of abi3-1 was compared to that of the ABA deficient mutant abal-1. Seedlings were grown for 12 days on the indicated media before seed germination and seedling greening were scored (b)

necessarily parallel (+)-ABA insensitivity (Nambara et al. 2002). Next, these mutants were plated on control, sorbitoland glucose-containing media, respectively. On $7 \%$ glucose media strong gin phenotypes were observed for abi4l gin6 and abi5 mutants as shown by the high percentages of greening, in agreement with earlier reports (Arenas-Huertero et al. 2000; Huijser et al. 2000; Laby et al. 2000). Again a strong gin phenotype was observed for abi3, in agreement with our observation using abi3-1 and abi3-5 mutants. Five out of the six additional abi3 mutants tested show a gin phenotype. For four abi3 mutants the gin phenotype was comparable to that of abi4-3 and abi5-7 (Table 3). The strong ABA insensitive abi3 mutants are strong gin mutants as well whereas the mutants with a weaker phenotype (abi3-11 and abi3-12) show a weaker phenotype on glucose media. However, exceptionally abi313 shows a weak abi phenotype but a strong gin phenotype. The abi3-11 mutant lacks an ABI insensitive phenotype 
Table 2 Relative expression levels of ABI3, ABI5, EM1, EM6 and RAB18 after glucose treatment

\begin{tabular}{|c|c|c|c|c|}
\hline Gene & Treatment & Exp. 1 & Exp. 2 & Exp. 3 \\
\hline \multirow[t]{5}{*}{$A B I 3$} & $\mathrm{t}=0$ & 1 & 1 & 1 \\
\hline & con & 0.14 & 0.09 & 0.06 \\
\hline & sorb & 2.2 & 0.19 & 1.7 \\
\hline & glc & 9.0 & 4.5 & 7.9 \\
\hline & $\mathrm{ABA}$ & 17 & 8.3 & 6 \\
\hline \multirow[t]{5}{*}{$A B I 5$} & $\mathrm{t}=0$ & 1 & 1 & 1 \\
\hline & con & 0.48 & 0.20 & 0.29 \\
\hline & sorb & 8.7 & 0.41 & 12 \\
\hline & glc & 19 & 13 & 19 \\
\hline & ABA & 40 & 41 & 23 \\
\hline \multirow[t]{5}{*}{$E M 1$} & $\mathrm{t}=0$ & 1 & 1 & 1 \\
\hline & con & 0.26 & 0.34 & 0.20 \\
\hline & sorb & 74 & 0.71 & 164 \\
\hline & glc & 79 & 72 & 300 \\
\hline & $\mathrm{ABA}$ & 749 & 742 & 200 \\
\hline \multirow[t]{5}{*}{ EM6 } & $\mathrm{t}=0$ & 1 & 1 & 1 \\
\hline & con & 0.22 & 0.14 & 0.15 \\
\hline & sorb & 36 & 0.38 & 78 \\
\hline & glc & 51 & 40 & 173 \\
\hline & $\mathrm{ABA}$ & 450 & 132 & 237 \\
\hline \multirow[t]{5}{*}{$R A B 18$} & $\mathrm{t}=0$ & 1 & 1 & 1 \\
\hline & con & 0.16 & 0.12 & 0.00 \\
\hline & sorb & 77 & 0.46 & 1.7 \\
\hline & glc & 324 & 41 & 6.2 \\
\hline & $\mathrm{ABA}$ & 6186 & 333 & 15 \\
\hline
\end{tabular}

The relative expression levels of five genes were determined using quantitative RT-PCR. The gene expression levels were measured at $\mathrm{t}=0$ and after a $24 \mathrm{~h}$ treatment on control media (con, half-strength MS $+1 \%$ sucrose) and on con media supplemented with either $8 \%$ sorbitol (sorb), $8 \%$ glucose (glc) or $10 \mu \mathrm{M}$ ABA (ABA) media. The expression level at $\mathrm{t}=0$ was set to 1 . The experiment was performed three times and the results for each experiment are indicated

and did not show a gin phenotype either. In conclusion, gin phenotype analysis of eight abi3 alleles confirms the glucose insensitive phenotype for abi3. Moreover, the gin phenotype of abi3 is comparable to that of other known gin mutants like abal, abi4 and abi5.

Glucose-induced expression of $A B I 4, A B I 5$ and $R A B 18$ is reduced in abi3

Glucose-induced early seedling developmental arrest is associated with expression of $A B I 3, A B I 4, A B I 5$ and a subset of LEA genes (Arenas-Huertero et al. 2000; Cheng et al. 2002; Arroyo et al. 2003; this study). The involvement of $A B I 3$ in glucose-regulated gene expression was tested for three genes $A B I 4, A B I 5$ and $R A B 18$ as a representative of the $L E A$ genes. For expression analysis the weak abi3-1 and the strong abi3-5 mutants were used.
Seedlings of all three genotypes were grown for $24 \mathrm{~h}$ on control media or on control media containing $8 \%$ glucose.

Both $R A B 18$ and $A B I 5$ expression were sensitive to glucose addition. In WT seedlings, glucose treatment induced these two genes on average 14 times in comparison to $\mathrm{t}=0$ (Fig. 5a, c). However, on glucose the expression levels of both genes were much reduced in abi3-1 and abi3-5 compared to WT (Fig. 5a, c). Glucose treatment did not result in a clear induction of $A B I 4$, especially when compared to $A B I 5$ and $R A B 18$. Instead $A B I 4$ expression was roughly maintained to the same level observed for $\mathrm{t}=0$ but was enhanced when compared to the control treatment which displayed a strong reduction of $A B I 4$ expression (Fig. 5b). ABI4 transcripts were $2-8$ fold lower in the abi3 mutant backgrounds upon glucose treatment. Thus, the abi3 mutation did not allow full glucose-induced expression of RAB18, ABI4 and ABI5. Interestingly, the reduced expression is most pronounced in the strong abi3-5 mutant background.

Already at $\mathrm{t}=0$ reduced expression levels for all three genes were observed in the abi3 mutant backgrounds. This was expected since the $A B I$ transcription factors were found to affect each others expression in seeds (Söderman et al. 2000). Moreover, $A B I 3$ is an important regulator of LEA gene expression (Parcy et al. 1994; Kermode 2005). To rule out that this reduced expression is responsible for the phenotype observed after glucose treatment the gene expression ratios of WT over mutant were determined for $\mathrm{t}=0$ and after glucose feeding. For each gene the expression level of WT is divided by the expression level of each mutant. These values show the fold difference of expression between WT and both abi3 mutants (Fig. 5d). E.g. the level of $R A B 18$ expression is 9 fold higher in WT compared to abi3-1 at $\mathrm{t}=0$. After glucose treatment the fold difference for $R A B 18$ expression was 38. Except for the ABI4 expression ratio of Ler-0 over abi3-1, all WT/ mutant expression ratios showed increased values after glucose exposure. This confirms that both mutants have a reduced ability to control glucose-regulated gene expression.

Other sugar insensitive phenotypes of abi3

The sugar response phenotype of the abi3-1 mutant was investigated in the sis, sun and glucose-induced delay of germination assays. High sucrose concentrations block early seedling development similar to high glucose concentrations. High sucrose resistant mutants are known as sis mutants (Laby et al. 2000). Several mutants affected in the same genes were retrieved from gin and sis screens, e.g. gin $1 /$ sis4/aba2, gin6/sis5/abi4 and gin4/sis1/ctr1. The sis phenotype of WT Ler-0, abi3-1 and abi3-5 was analysed by plating these genotypes on $13 \%$ sucrose media. Both 

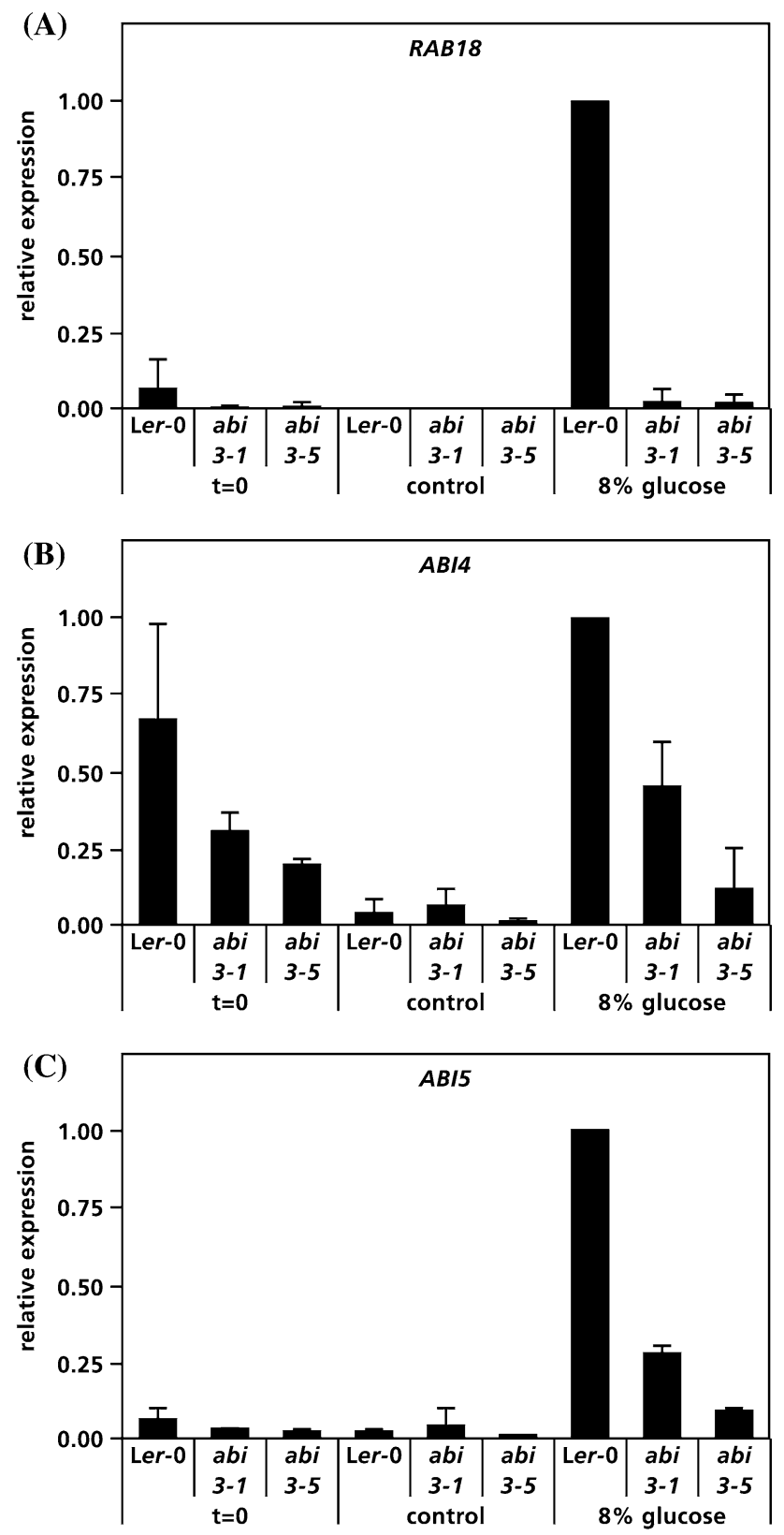

\begin{tabular}{lccc}
\hline \multirow{2}{*}{ D) } & & \multicolumn{2}{c}{ Expression ratio Ler-0/abi3 } \\
\cline { 3 - 4 } & gene & at $\mathrm{t}=0$ & after $24 \mathrm{~h}$ glc \\
\hline Expression & $R A B 18$ & 9.3 & 38.5 \\
Ler-0 over & $A B I 4$ & 2.3 & 2.2 \\
abi3-1 & $A B I 5$ & 2.1 & 3.5 \\
\hline Expression & $R A B 18$ & 4.1 & 62.5 \\
Ler-0 over & $A B I 4$ & 3.4 & 8.3 \\
abi3-5 & $A B I 5$ & 3.4 & 10.3 \\
\hline
\end{tabular}

abi3 mutants show a sucrose insensitive phenotype (Fig. 6a, b) and can thus be considered as sis as well as gin mutants.

Dijkwel et al. (1997) previously reported on sugar insensitive mutants that have been isolated using the sun
4Fig. 5 Altered glucose-regulated gene expression in abi3 mutants. Glucose-regulated gene expression was studied in WT Ler-0 and abi3-1 and abi3-5 mutants. Gene expression was quantified by qRTPCR at $\mathrm{t}=0$, the time of glucose application and after $24 \mathrm{~h}$ on control medium (con, half-strength MS $+1 \%$ sucrose) or con medium supplemented with $8 \%$ glucose. At the $\mathrm{t}=0$ time point approximately $70 \%$ of the seeds had germinated. The values indicate an average of three independent experiments (two experiments for abi3-5). The WT Ler-0 expression on $8 \%$ glucose was set to one in each experiment. The glucose-regulated expression in Ler-0 and the two abi3 mutants was studied for $R A B 18$ (a), $A B I 4$ (b) and $A B I 5$ (c). The gene expression ratio of Ler-0 over abi3 was calculated because all three genes were already under expressed in abi3-1 and abi3-5 at $\mathrm{t}=0$. This ratio was calculated by dividing the average gene expression in Ler-0 by the expression in abi3 (for both mutants) at $\mathrm{t}=0$ and after $8 \%$ glucose treatment for all three genes $(\mathbf{d})$

screen. Dark-grown seedlings transiently express photosynthesis genes, including plastocyanin $(P C$, Dijkwel et al. 1996). This transient increase of photosynthesis gene expression is repressed on sucrose media. In sun mutants sucrose did not repress this transient $P C$ gene expression in dark grown seedlings (Dijkwel et al. 1997). sun6 is such a mutant which was shown to be allelic to abi4 (Huijser et al. 2000). A possible sun phenotype of abi3-1 was investigated by quantifying $P C$ mRNA levels in two days old, dark-grown seedlings using qRT-PCR. Elevated $P C$ expression was observed in sucrose-treated seedlings of sun6/abi4-3 compared to its WT PC-LUC parent confirming its sun phenotype (Fig. 6c). Interestingly, the abi31 mutant showed enhanced $P C$ expression as well and, therefore, abi3 has a sun phenotype (Fig. 6c). abi4 mutants displayed a nine fold increased $P C$ expression level in sugar-treated seedlings compared to WT. In the abi3 mutants the $P C$ expression level is only two fold increased, indicating that abi3 is a weak sun mutant.

Sugars delay seed germination in Arabidopsis. ABA plays a role in this glucose-induced delay of germination (Ullah et al. 2002; Price et al. 2003; Dekkers et al. 2004; Chen et al. 2006). Despite the involvement of ABA, several $a b i$ mutants (abil-1, abi2-1, abi4 and abi5) are normally sensitive to glucose during germination (Price et al. 2003; Dekkers et al. 2004). Sugar insensitive mutants like gin6/ abi4 and gin2/hxkl that are insensitive to the glucoseinduced early seedling developmental arrest are sensitive to glucose during germination (defined as radicle emergence). This indicates that the glucose response during germination (which delays radicle protrusion) and early seedling growth (which arrests seedling development) are two distinct processes (Price et al. 2003; Dekkers et al. 2004). The, abi3-1 and abi3-5 alleles were plated on $2.5 \%$ glucose. The presence of $2.5 \%$ glucose clearly delayed germination of WT seeds. The osmotic control of $2.5 \%$ sorbitol only slightly affected germination compared to control media. Both abi3 mutants showed a clear resistance against glucose as displayed by their reduced germination delay (data not shown), 

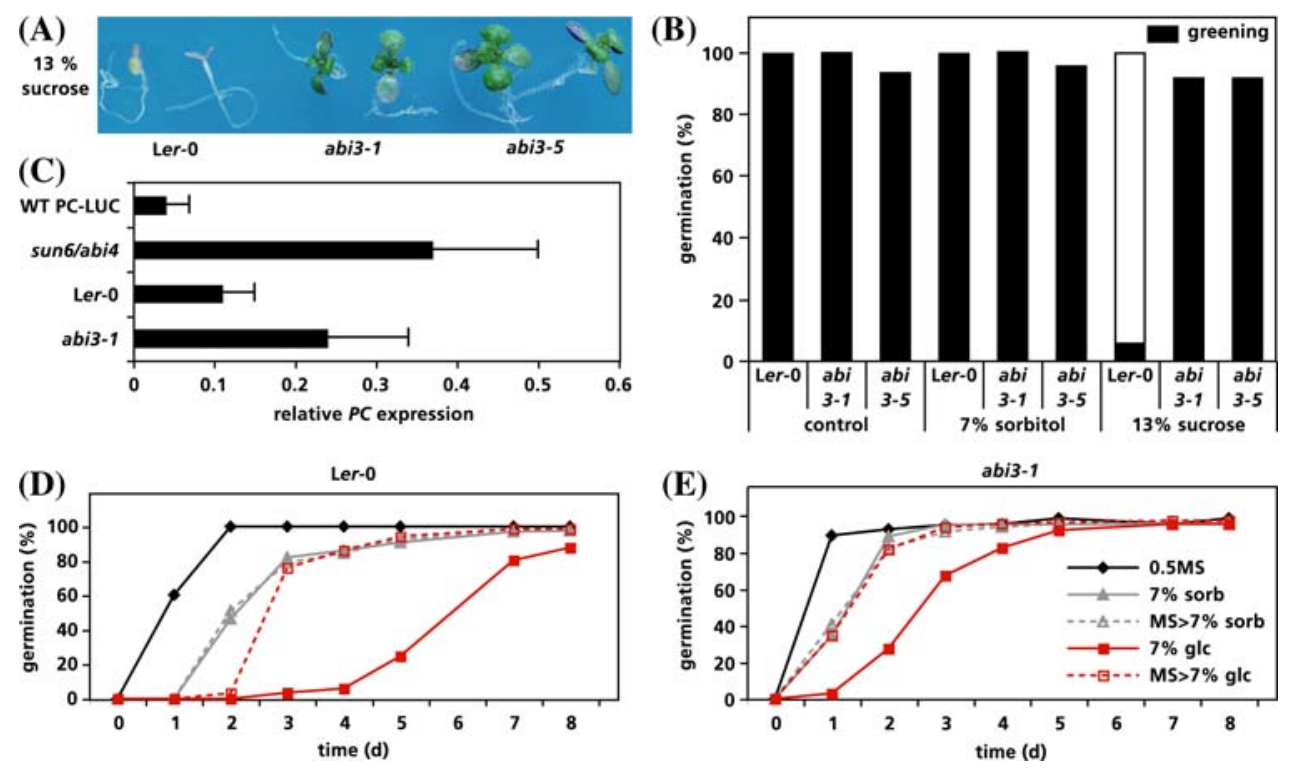

Fig. 6 The abi3-1 mutant shows additional sugar signalling defects. The sugar response phenotype of abi3-1 was assessed in three additional assays. The sugar insensitive (sis) phenotype was assessed by scoring the early seedling developmental phenotype (by seedling greening) after growth on elevated sucrose concentration. Representative Ler-0, abi3-1 and abi3-5 seedling phenotypes are shown after growth on $13 \%$ sucrose media for 13 days (a). The percentage of germination and seedling greening of Ler-0, abi3-1 and abi3-5 was determined after growth for 13 days on control (half-strength MS $+1 \%$ sucrose) or on control medium supplemented with either $7 \%$ sorbitol or $13 \%$ sucrose media (b). The sucrose uncoupled (sun) phenotype was assessed by measuring plastocyanin $(P C)$ expression levels by qRT-PCR in two days old seedlings grown on sucrose containing media in darkness. Sucrose repressed the $P C$ transcript level in dark-grown two days old WT seedlings in comparison to WT seedlings grown on sugar-free media, however in sun mutants $P C$

which is in agreement with observations of Yuan and Wysocka-Diller (2006) who reported on the glucose insensitivity of abi3-1 during germination.

In our experiments seeds were sterilized, plated on sugar media, and after a three day stratification period moved to the growth chamber and germination was scored the following days. Interestingly, when WT seeds were stratified on sugar-free media (half-strength MS) and after stratification transferred to sugar-containing plates, the delay of germination by $2.5 \%$ glucose was completely lost (data not shown). Thus, stratification on sugar-free media suppressed the inhibitory effect of glucose on germination. This effect of stratification was further investigated using higher (7\%) glucose and sorbitol concentrations. Ler-0 and abi3-1 seeds were plated either on control, sorbitol or glucose media, stratified for three days and moved to the growth chamber. Alternatively, seeds were stratified on sugar-free control media and shifted to media containing sorbitol or glucose, and then placed in the growth chamber. Continuous treatment with $7 \%$ glucose severely delayed germination of WT

repression by sucrose is much less pronounced (Dijkwel et al. 1997). Indicated are the relative $P C$ expression on sucrose containing media for WT PC-LUC and sun6/abi4 (assayed on 2\% sucrose) and Ler-0 and abi3-1 (assayed on 1\% sucrose). Values indicate an average of at least three experiments. $P C$ expression of two days old seedlings grown on sugar-free half-strength MS was set to 1 for each genotype in every experiment (c). Germination is delayed by glucose addition. abi3-1 was tested for glucose-induced delay of germination by plating seeds on half-strength MS (0.5 MS), $0.5 \mathrm{MS}+7 \%$ sorbitol $(7 \%$ sorb) and $0.5 \mathrm{MS}+7 \%$ glucose $(7 \%$ glc). Sugars were already present during stratification (solid lines). In addition, seeds were stratified on sugar-free $0.5 \mathrm{MS}$ media and directly after stratification transferred to $0.5 \mathrm{MS}+7 \%$ sorbitol (MS $>7 \%$ sorb) and $0.5 \mathrm{MS}+$ $7 \%$ glucose (MS $>7 \%$ glc, dashed lines). Seed germination after the different treatments was scored daily for eight days for Ler-0 (d) and abi3-1 (e)

seeds but affected abi3-1 significantly less as expected (Fig. 6d, e). Also in this experiment, stratification on sugarfree media strongly suppressed the germination response to glucose in WT Ler-0. Even germination of the abi3-1 mutant, which already showed a reduced sensitivity to glucose during germination could be improved by stratification on sugar-free media. The germination speed of the abi3-1 mutant after stratification on sugar-free media was similar to the osmotic control indicating that this combination completely suppressed the germination delay by glucose. The glucose response during germination was affected by stratification but not the osmotic response (sorbitol treatment). This was observed for WT Ler-0 as well as the abi3-1 mutant thereby differentiating glucose from osmotic signalling.

abi2-1 and eral-2 mutant are glucose response mutants

Our results on the physiological and molecular level indicate that glucose-arrested seedlings mimic ABA-arrested 

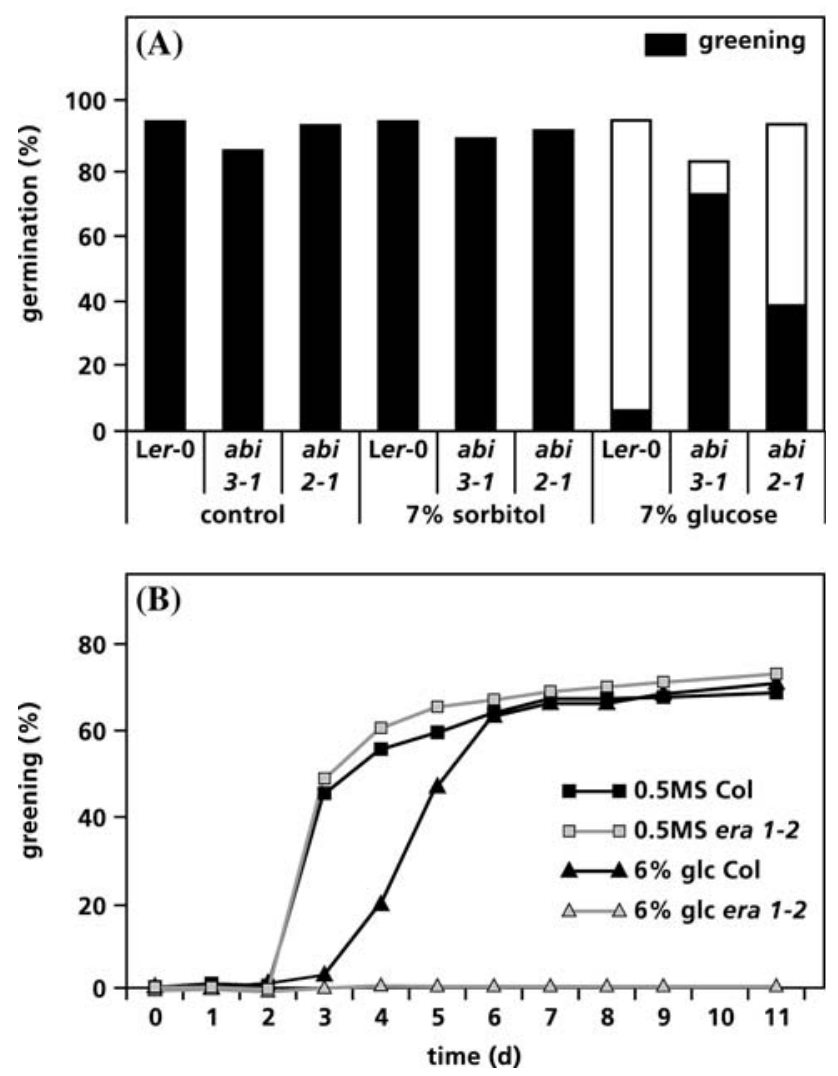

Fig. 7 Other ABA signalling mutants have sugar signalling defects as well. Putative glucose signalling defects were determined for the ABA insensitive mutant abi2-1 and the ABA oversensitive mutant era1-2. Ler-0, abi2-1 and abi3-1 were grown on control media (halfstrength MS $+1 \%$ sucrose), or on control medium supplemented with either $7 \%$ sorbitol or $7 \%$ glucose. After 12 days germination and seedling greening percentage were scored (a). To investigate whether eral-2 has a glucose oversensitive phenotype both WT Col and mutant were grown on a sugar concentration which did not arrest early development of WT Col. Therefore, seedling greening of Col and the eral-2 mutant was scored daily on half-strength MS (0.5 MS) and on $0.5 \mathrm{MS}+6 \%$ glucose. The seedling phenotype was scored for 11 days $(\mathbf{b})$

seedlings. The finding that $A B I 3$ is important for glucose signalling in addition to $A B I 4$ and $A B I 5$ led us to test the glucose insensitive phenotype of two other $\mathrm{ABA}$ signalling mutants, i.e. abi2-1 and eral. Brady et al. (2003) proposed a genetic pathway for $E R A I$ and the $A B I 1-A B I 5$ genes in seed ABA responsiveness based on double mutant analysis between the eral mutant and the abi mutants. This analysis suggested that $A B I 1$ and $A B I 2$ act at or upstream of ERAI, while ERAI acts at or upstream of $A B I 3, A B I 4$ and $A B I 5$ (Brady et al. 2003). $A B I 2$ encodes a phosphatase $2 \mathrm{C}$ protein that acts as a negative regulator of $\mathrm{ABA}$ signalling and the abi2-1 mutation results in an ABA insensitive phenotype (Koornneef et al. 1984; Leung et al. 1997). WT Ler-0 and abi2- 1 seeds were plated along with abi3-1 on control, $7 \%$ sorbitol and $7 \%$ glucose media. In addition to abi3, the abi2-1 mutant displayed a gin phenotype as well, although its phenotype is not as strong as that of abi3-1 (Fig. 7a). On control and sorbitol media all seedlings showed greening.

The ERAl gene encodes a $\beta$ subunit of a protein farnesyl transferase (Cutler et al. 1996) and acts as a negative regulator of $\mathrm{ABA}$ signalling. The eral-2 mutant has an ABA hypersensitive phenotype. If ERAl exerts a similar function in glucose signalling, a glucose oversensitive ( $\mathrm{glo}$ ) phenotype is expected for the eral-2 mutant. Seeds of WT $\mathrm{Col}$ and eral-2 were plated on half-strength MS $+6 \%$ glucose media. This glucose concentration allowed seedling greening of the WT Col seedlings. Greening started for WT seedlings from day four onwards. However, this glucose concentration arrested early seedling development of eral-2 seedlings. Even after eleven days no greening was observed for eral-2 seedlings (Fig. 7b), which indicates that eral-2 indeed has a glo phenotype. The eral-2 mutant has a more dormant phenotype compared to WT (Cutler et al. 1996). Therefore, seed germination was synchronized as much as possible by using after-ripened seeds and employing a three day stratification period on sugar-free media. On control media (half-strength MS) germination was somewhat delayed but that did not affect cotyledon greening. On 6\% glucose eral-2 germination reached similar germination levels as WT seeds despite that germination was 1-2 days delayed (data not shown). This slower germination of eral-2 does not explain the much larger difference observed for cotyledon greening on glucose media. Thus, the small difference in germination timing between eral-2 and WT is not responsible for the seedling greening phenotype.

\section{Discussion}

GLUCOSE INSENSITIVE signalling depends on a functional $A B I 3$ gene

Our results show that $A B I 3$ is an essential regulator of $G I N$ signalling. This conclusion is based on three observations. Firstly, $A B I 3$ transcript levels accumulate in response to glucose treatment. In our study seedlings were treated for a relatively short period of $24 \mathrm{~h}$ and showed a 5-9 fold enhanced $A B I 3$ levels, while $A B I 3$ expression levels dropped after $24 \mathrm{~h}$ growth on control media (Table 2). The osmotic control conditions induced $A B I 3$ expression at most two fold showing that the strong induction of $A B I 3$ by glucose is not solely due to osmotic stress. Secondly, glucose-regulated gene expression was altered in the abi3 mutant background. Glucose enhanced the expression of $L E A$ genes and two important regulators of GIN signalling $A B I 4$ and $A B I 5$. In WT, glucose treatment led to a 14 fold induction of $R A B 18$ and $A B I 5$, and a 1.5 fold induction of $A B I 4$. The abi3 mutation caused 2-60 fold under 
Table 3 Glucose insensitive phenotype of six abi3 alleles

\begin{tabular}{lrrrcc}
\hline Genotype & \multicolumn{5}{l}{ Treatment } \\
\cline { 2 - 6 } & con & $7 \%$ sorb & $7 \%$ glc & $10 \mu \mathrm{M} \mathrm{ABA}$ & $3 \mu \mathrm{M} \mathrm{ABA}^{\mathrm{a}}$ \\
\hline WT Col & 100 & 99 & 2 & 0 & 0 \\
abi4-3 & 99 & 98 & 94 & 100 & 100 \\
abi5-7 & 99 & 98 & 89 & 96 & 100 \\
abi3-8 & 100 & 100 & 97 & 91 & 100 \\
abi3-9 & 100 & 100 & 100 & 100 & 100 \\
abi-310 & 100 & 100 & 100 & 100 & 100 \\
abi3-11 & 100 & 100 & 5 & 2 & 0 \\
abi3-12 & 100 & 96 & 33 & 83 & 50 \\
abi3-13 & 100 & 100 & 98 & 40 & 0
\end{tabular}

Seeds of WT Col, abi4-3, abi5-7 and six abi3 mutants were stratified on half-strength MS and after stratification switched to control medium (con, $0.5 \mathrm{MS}+1 \%$ sucrose) or con medium containing $7 \%$ sorbitol, $7 \%$ glucose or $10 \mu \mathrm{M}$ ABA. Values are the percentage of cotyledon greening scored after 11 days. The experiment was repeated once with similar results

a The ABA insensitivity scored for the different mutant alleles based on cotyledon greening by Nambara et al. (2002)

expression of these glucose-regulated genes (Fig. 5). Thirdly, we observed a gin phenotype for seven out of eight abi3 alleles in both Ler- 0 and $\mathrm{Col}$ accessions. The majority of the abi3 alleles tested showed a gin phenotype that was comparable to well-known gin mutants like abal, abi4 and abi5 (Fig. 4 and Table 3). This indicates that $A B I 3$ is a key regulator of GIN signalling which is in agreement with previous reports showing that $A B I 3$ overexpression (either AtABI3 or $C n A B I 3)$ in Arabidopsis results in a glucose oversensitive phenotype (Finkelstein et al. 2002; Zeng and Kermode 2004). Kermode (2005) distinguished at least three functions for $A B I 3$ in seeds. (i) dormancy induction and maintenance (ii) induction of storage proteins and desiccation/stress protectants and (iii) repression of postgerminative gene expression. The observations that abi3 mutants showed a disturbed glucose-regulated induction of $R A B 18$ and a gin phenotype (lack of post-germinative gene repression) are in agreement with the functions defined for ABI3.

Although a role for $A B I 3$ in sugar signalling during early seedling development was hinted by $A B I 3$ over expression lines (Finkelstein et al. 2002; Zeng and Kermode 2004) and the observation that abi3 mutants were insensitive to glucose in combination with ABA (Nambara et al. 2002) its role remained controversial. This because studies that investigated the gin phenotype of abi3-1 in the Ler-0 background observed at most a weak phenotype. Importantly however, Ler-0 is a sugar oversensitive accession compared to the Col accession (Laby et al. 2000) and likely, the sugar insensitive phenotype of abi3-1 has been underestimated in comparison with mutants in genetic backgrounds that show more rapid greening. Further, the absence of a clear gin phenotype for abi3-1 in earlier studies could be due to the seed material used. We observed that freshly harvested seeds were particularly sensitive to sugars during germination (data not shown). Low sugar concentrations delay germination while higher levels resulted in severely reduced germination rates. Therefore, we routinely after-ripened seeds for at least a month before these were used in our sugar signalling experiments. Seed quality changes per batch produced, which affects germination and most likely responses to internal and external stimuli as well. Hence, WT and mutant seeds used in the sugar response assays were produced simultaneously under the same growth conditions and seeds were stored under identical conditions. Moreover, we routinely stratified the seeds on sugar-free halfstrength MS media before the start of the gin assays, since this procedure dramatically improves germination rates following transfer to glucose-containing media (Fig. 6d; Dekkers and Smeekens 2007). Under these conditions we were able to obtain clear gin phenotypes within 12-14 days for abi3 in the Ler-0 background.

In addition, this study identified both abi3-1 and abi3-5 as sis mutants (which are insensitive for the sucroseinduced early seedling developmental arrest, Laby et al. $2000)$ as well. In addition, abi3 mutants are insensitive to the glucose-induced delay of germination (Yuan and Wysocka-Diller 2006; Fig. 6d, e) and abi3 is a weak sun mutant. These observations imply a broader role for $A B I 3$ in mediating sugar responsiveness. Interestingly, another B3 domain transcription factor, HSI2, was found to regulate the sugar-inducible sporamin promoter (Tsukagoshi et al. 2005). HSI2 is an active transcriptional repressor. A mutation in this gene causes high sporamin promoter activity in both low and high sugar conditions.

\section{Glucose and $\mathrm{ABA}$ induce a similar early seedling arrest} in Arabidopsis

Glucose treatment of germinated seeds resulted in an enhanced expression of several transcriptional regulators of late seed maturation ( $A B I 3, A B I 4$ and $A B I 5)$. GIN signalling depends on these glucose-induced factors as shown by mutant analysis (León and Sheen 2003; this study). LEA genes (EM1, EM6 and RAB18) were also induced by glucose treatment. The $A B I$ transcription factors are known to regulate the expression of LEA genes (Parcy et al. 1994; Finkelstein et al. 1998; Finkelstein and Lynch 2000; Carles et al. 2002; Kermode 2005). LEA gene expression is correlated with drought and desiccation tolerance (Hoekstra et al. 2001) and its enhanced expression is in agreement with the drought tolerant phenotype observed for glucosearrested seedlings. Interestingly, the ABA response during 
the post-germination developmental arrest depends on the same $A B I 3, A B I 4$ and $A B I 5$ transcription factors. ABA similarly induces $A B I 3, A B I 5$ and a subset a $L E A$ genes. Lopez-Molina et al. (2001; 2002) suggested that a late embryogenesis program was re-induced by ABA, which resulted in developmentally arrested, drought tolerant seedlings and that this may constitute an important checkpoint during germination and seedling development.

The developmentally arrested state could only be induced within a limited time frame and after 60-72 h ABA sensitivity was lost. Beyond this limited time window ABA did not induce ABI3 and ABI5 protein levels, nor, re-induce $L E A$ gene transcription and did not block early seedling development. The sugar-induced seedling arrest is restricted to a similar time window (Gibson et al. 2001). Following this time window glucose failed to re-induce $A B I 3, A B I 5$ and $L E A$ genes. Thus far it is not clear whether this time frame specifies a sugar sensitive window. Since ABA insensitivity results in a gin phenotype the loss of ABA sensitivity beyond this time frame may account for the glucose insensitivity observed. In conclusion, both glucose and ABA signalling depend on the same set of genes, induce similar transcription factors and LEA genes, result both in drought tolerant phenotypes and are sensitive for a similar time window. This indicates that both trigger a similar seedling developmental arrest.

Interestingly, the induction of desiccation tolerance in germinated radicles is limited to a small time window after germination as well. In germinated seeds with short radicles $(<3 \mathrm{~mm})$ desiccation tolerance can be induced while in seeds with longer radicles $(>4 \mathrm{~mm})$ this capacity is lost (Buitink et al. 2003). Possibly, this phenomenon depends on the same genetic components and is sensitive in a similar time window observed for glucose- and ABAinduced post-germination developmental block. A possible role was suggested for sugar signalling in desiccation tolerance induction in barrel medic (Medicago truncatula) and cucumber (Cucumis sativa) radicles (Leprince et al. 2004). Non-reducing di- and trisaccharides, e.g. sucrose, protect the structure of membranes and proteins by the formation of a glassy state (Koster 1991; Hoekstra et al. 2001). E.g. elevated sucrose concentrations were measured in desiccation tolerant radicles (Koster and Leopold 1988; Bruggink and van der Toorn 1995). Our study suggests that such elevated sugar concentrations may serve a double role, by protecting cellular structures and by acting as a signal for the induction of protectants such as LEA protein.

Interactions between sugar and ABA signalling

The early seedling developmental arrest phenotype has been extensively exploited to isolate mutants with sugar signalling defects like gin mutants (Rognoni et al. 2007).
The gin $2 / h x k 1$ mutant revealed a role for $H X K 1$ in glucose signalling. Such $H X K 1$ signalling does not depend on its metabolic function (Moore et al. 2003) and HXK1 was shown to interact with unusual partners (a vacualor $\mathrm{H}^{+}$-ATPase and a $19 \mathrm{~S}$ proteasome subunit) to regulate glucose signalling (Cho et al. 2006). Other gin mutants suggested a link between glucose signalling and plant hormone biosynthesis and signalling. The lack of ABA biosynthesis and signalling (gin1/aba2, gin5/aba3 and gin6/abi4) resulted in glucose insensitivity. To study the interaction between ABA biosynthesis, ABI4 and sugar signalling we used ABA deficient lines with constitutive ABI4 expression (aba2-1/35S::ABI4). These strong ABI4 overexpression lines affected $A p L 3$ expression (ISI pathway) and showed a stunted growth phenotype similar to what has been reported previously for severe $A B I 4$ overexpression lines (Söderman et al. 2000), indicating that $A B I 4$ is active in an ABA deficient background. Nevertheless, the gin phenotype of aba2-1 could not be restored by high $A B I 4$ expression levels (Fig. 1c). Thus, $A B I 4$ is necessary but not sufficient for GIN signalling in an ABA deficient background, indicating that other $\mathrm{ABA}$ regulated factors are essential for proper GIN signalling as well. Both $I S I$ and GIN signalling rely on ABA biosynthesis and $A B I 4$ but surprisingly, $A B I 4$ overexpression only affected the isi phenotype of aba2-1. Thus, gin and isi sugar signalling depend on the same components but this study shows that the relationship between sugar, ABA and ABI4 is different for both sugar signalling pathways.

ABA biosynthesis and ABA signalling are required for the sugar induced seedling arrest. Genetic studies showed that two transcription factors which are involved in ABA signalling, i.e. $A B I 4$ and $A B I 5$, function in the sugarinduced seedling arrest (Arenas-Huertero et al. 2000; Huijser et al. 2000; Laby et al. 2000; Brocard et al. 2002). Here we show that $A B I 3$ is also essential for GIN signalling. Glucose induces ABA biosynthesis genes (Cheng et al. 2002) and increased ABA levels were measured in developmentally arrested seedlings. ABA is able to induce $A B I 3$ transcription (Table 2) and affects $\mathrm{ABI} 3$ protein stability (Zhang et al. 2005). Thus glucose may impinge on $A B I 3$ via activation of $\mathrm{ABA}$ biosynthesis. $A B I 3$ also functions in seed development and developmental timing (Rohde et al. 1999, 2000). Severe abi3 mutant embryos remain green and are unable to acquire desiccation tolerance and dormancy during seed development (Ooms et al. 1993). Such mature abi3 embryos resemble a developing seedling rather than a dormant embryo (Nambara et al. 1995). The seedling developmental arrest as induced by ABA and glucose is sensitive to developmental signals as well. Arrest of seedling development by ABA and sugars only occurs within a two to three days time window after imbibition (Gibson et al. 2001; Lopez-Molina et al. 2001). 
Therefore, the phenotype of the severe abi3 mutants is probably not solely due to ABA insensitivity but to seed developmental defects and the heterochronic nature of this mutation as well.

Two additional ABA response mutants with altered glucose responsiveness, abi2 and eral, strengthen the link between glucose and ABA signalling. The abi2-1 mutant showed a gin phenotype that is weaker compared to abi3-1. Possibly additional seed developmental phenotypes of abi3 may explain the stronger phenotype of the abi3-1 mutant compared to abi2-1. However, the ABA insensitive phenotype of abi2-1 is somewhat weaker compared to abi3-1 (Koornneef et al. 1984; Finkelstein and Somerville 1990), which could explain the weaker gin phenotype as well. The eral-2 mutant is hypersensitive to ABA and shows a glucose oversensitive phenotype. Interestingly, era3 another ABA hypersensitive mutant shows a similar glo phenotype. Era3 is allelic to ethylene insensitive2 (ein2, Ghassemian et al. 2000) and also other ethylene related mutants show sugar signalling defects (Zhou et al. 1998; Gibson et al. 2001; León and Sheen 2003).

The role of $\mathrm{ABA}$ and $\mathrm{ABA}$ signalling in sugar signalling is well established. Thus far, sugar signalling was thought to rely on only a part of the ABA signalling cascade. The analysis of aba2/35S::ABI4 transgenic lines showed that $\mathrm{ABA}$ related factors other than $A B I 4$ are involved in glucose signalling. Furthermore, the glucoseinduced early seedling arrest mimics the ABA-induced seedling arrest. Our study indicates that all response loci tested that act in the genetic pathway regulating $\mathrm{ABA}$ responsiveness as proposed by Brady et al. (2003) affect glucose signalling. These observations suggest that the genetic pathways regulating glucose and ABA signalling are much more closely linked than assumed thus far. Obviously, both pathways are different as well. Genetic analysis suggested that $H X K 1$ acts upstream of $\mathrm{ABA}$ signalling in glucose signalling. Moreover, the gaolaozhuangren 2 mutant has a gin phenotype but is not affected in ABA signalling (Chen et al. 2004). Such mutants may provide insight in the mechanism by which glucose affects ABA signalling. Interestingly, glucose delays germination in a process that depends on $A B I 3$ but that does not require $A B I 1, A B I 2 A B I 4$ and $A B I 5$ (Gibson 2005; Yuan and Wysocka-Diller 2006; Fig. 6d, e), showing that the tight interaction between glucose and $\mathrm{ABA}$ is not present in all sugar response pathways.

Acknowledgements We like to thank Dr. E. Nambara, Dr. T. Peeters and the Nottingham Arabidopsis Stock Centre (NASC) for providing seeds, Ronald Leito and Frits Kindt for skilful photography and Frouke Kuijer for preparing the figures. This research was supported by the Earth and Life Science Foundation subsidized by the Netherlands Organization for Scientific Research and a grant of the Department of Biology of the Utrecht University.
Open Access This article is distributed under the terms of the Creative Commons Attribution Noncommercial License which permits any noncommercial use, distribution, and reproduction in any medium, provided the original author(s) and source are credited.

\section{References}

Acevedo-Hernandez GJ, León P, Herrera-Estrella LR (2005) Sugar and ABA responsiveness of a minimal RBCS light-responsive unit is mediated by direct binding of ABI4. Plant $\mathrm{J}$ 43: 506-519

Akihiro T, Mizuno K, Fujimura T (2005) Gene expression of ADPglucose pyrophosphorylase and starch contents in rice cultured cells are cooperatively regulated by sucrose and ABA. Plant Cell Phys 46:937-946

Arenas-Huertero F, Arroyo A, Zhou L, Sheen J, León P (2000) Analysis of Arabidopsis glucose insensitive mutants, gin 5 and gin6, reveals a central role of the plant hormone ABA in the regulation of plant vegetative development by sugar. Genes Dev 14:2085-2096

Arroyo A, Bossi F, Finkelstein RR, León P. (2003) Three genes that affect sugar sensing (abscisic acid insensitive 4, abscisic acid insensitive 5, and constitutive triple response 1) are differentially regulated by glucose in Arabidopsis. Plant Physiol 133:231-242

Brady SM, Sarkar SF, Bonetta D, McCourt P (2003) The ABSCISIC ACID INSENSITIVE3 (ABI3) gene is modulated by farnesylation and is involved in auxin signaling and lateral root development in Arabidopsis. Plant J 34:67-75

Brocard IM, Lynch TJ, Finkelstein RR (2002) Regulation and role of the Arabidopsis ABSCISIC ACID-INSENSITIVE 5 gene in abscisic acid, sugar, and stress response. Plant Physiol 129: $1533-1543$

Brocard-Gifford I, Lynch TJ, Garcia ME, Malhotra B, Finkelstein RR (2004) The Arabidopsis thaliana ABSCISIC ACID-INSENSITIVE 8 locus encodes a novel protein mediating abscisic acid and sugar responses essential for growth. Plant Cell 16:406-421

Bruggink T, van der Toorn P (1995) Induction of desiccation tolerance in germinated seeds. Seed Sci Res 5:1-4

Buitink J, Ly Vu B, Satour P, Leprince O (2003) The re-establishment of desiccation tolerance in germinated radicles of Medicago truncatula Gaertn. seeds. Seed Sci Res 13:273-286

Cakir B, Agasse A, Gaillard C, Saumonneau A, Delrot S, Atanassova R (2003) A grape ASR protein involved in sugar and abscisic acid signaling. Plant Cell 15:2165-2180

Carles C, Bies-Etheve N, Aspart L, Leon-Kloosterziel KM, Koornneef M, Echeverria M, Delseny M (2002) Regulation of Arabidopsis thaliana Em genes: role of ABI5. Plant J 30: 373-383

Chen M, Xia X, Zheng H, Yuan Z, Huang H (2004) The GAOLAOZHUAGREN2 gene is required for normal glucose response and development in Arabidopsis. J Plant Res 117: $472-476$

Chen Y, Ji F, Xie H, Liang J, Zhang J (2006) The regulator of Gprotein signaling proteins involved in sugar and abscisic acid signaling in Arabidopsis seed germination. Plant Physiol 140:302-310

Cheng WH, Endo A, Zhou L, Penney J, Chen HC, Arroyo A, León P, Nambara E, Asami T, Seo M, Koshiba T, Sheen J (2002) A unique short-chain dehydrogenase/reductase in Arabidopsis glucose signaling and abscisic acid biosynthesis and functions. Plant Cell 14:2723-2743

Cho Y-H, Yoo S-D, Sheen J (2006) Regulatory functions of nuclear hexokinase 1 complex in glucose signaling. Cell 127:579-589 
Clough SJ, Bent AF (1998) Floral dip: a simplified method for Agrobacterium-mediated transformation of Arabidopsis thaliana. Plant J 16:735-743

Cutler S, Ghassemian M, Bonetta D, Cooney S, McCourt P (1996) A protein farnesyl transferase involved in abscisic acid signal transduction in Arabidopsis. Science 273:1239-1241

Dekkers BJW, Schuurmans JAMJ, Smeekens SCM (2004) Glucose delays seed germination in Arabidopsis thaliana. Planta 218:579-588

Dekkers BJW, Smeekens SCM (2007) Sugar and abscisic acid regulation of germination and transition to seedling growth. In: Bradford K, Nonogaki H (eds) Seed development, dormancy and germination. Blackwell Publishing, Oxford, UK, pp 305-327

Dijkwel PP, Kock PAM, Bezemer R, Weisbeek PJ, Smeekens SCM (1996) Sucrose represses the developmentally controlled transient activation of the plastocyanin gene in Arabidopsis thaliana seedlings. Plant Physiol 110:455-463

Dijkwel PP, Huijser C, Weisbeek PJ, Chua NH, Smeekens SCM (1997) Sucrose control of phytochrome A signaling in Arabidopsis. Plant Cell 9:583-595

Finkelstein RR, Gibson SI (2001) ABA and sugar interactions regulating development:cross-talk or voices in a crowd? Curr Opin Plant Biol 5:26-32

Finkelstein RR, Lynch TJ (2000) The Arabidopsis abscisic acid response gene ABI5 encodes a basic leucine zipper transcription factor. Plant Cell 12:599-610

Finkelstein RR, Somerville CR (1990) Three classes of abscisic acid (ABA)-insensitive mutations of Arabidopsis define genes that control overlapping subsets of ABA responses. Plant Physiol 94:1172-1179

Finkelstein RR, Wang ML, Lynch TJ, Rao S, Goodman HM (1998) The Arabidopsis abscisic acid response locus ABI4 encodes an APETALA 2 domain protein. Plant Cell 10:1043-1054

Finkelstein RR, Gampala SSL, Rock CD (2002) Abscisic acid signalling in seeds and seedlings. Plant Cell (Suppl) 14:S15-S45

Gazzarrini S, McCourt P (2001) Genetic interactions between ABA, ethylene and sugar signalling pathways. Curr Opin Plant Biol 4:387-391

Ghassemian M, Nambara E, Cutler S, Kawaide H, Kamiya Y, McCourt P (2000) Regulation of abscisic acid signaling by the ethylene response pathway in Arabidopsis. Plant Cell 12: $1117-1126$

Gibson SI (2000) Plant sugar-response pathways. Part of a complex regulatory web. Plant Physiol 124:1532-1539

Gibson SI (2004) Sugar and phytohormone response pathways: navigating a signalling network. J Exp Bot 55:253-264

Gibson SI (2005) Control of plant development and gene expression by sugar signaling. Curr Opin Plant Biol 8:93-102

Gibson SI, Laby RJ, Kim D (2001) The sugar-insensitive1 (sis1) mutant of Arabidopsis is allelic to ctr1. Biochem Biophys Res Commun 280:196-203

Giraudat J, Hauge BM, Valon C, Smalle J, Parcy F, Goodman HM (1992) Isolation of the Arabidopsis ABI3 gene by positional cloning. Plant Cell 4:1251-1261

Hoecker U, Vasil IK, McCarty DR (1995) Integrated control of seed maturation and germination programs by activator and repressor functions of Viviparous-1 of maize. Genes Dev 9:2459-2469

Hoekstra F, Golovina EA, Buitink J (2001) Mechanisms of plant desiccation tolerance. Trends Plant Sci 5:431-438

Huijser C, Kortstee A, Pego J, Weisbeek P, Wisman E, Smeekens S (2000) The Arabidopsis sucrose uncoupled-6 gene is identical to abscisic acid insensitive-4:involvement of abscisic acid in sugar responses. Plant J 23:577-585

Jang J-C, Sheen J (1997) Sugar sensing in higher plants. Trends Plant Sci 2:208-214
Kermode AR (2005) Role of abscisic acid in seed dormancy. J Plant Growth Regul 24:319-344

Koornneef M, Karssen CM (1994) Seed dormancy and germination. In: Meyerowitz EM, Somerville CR (eds) Arabidopsis. Cold Spring Harbor Laboratory Press, Cold Spring Harbor, NY, pp 313-334

Koornneef M, Reuling G, Karssen CM (1984) The isolation and characterization of abscisic acid-insensitive mutants of Arabidopsis thaliana. Physiol Plant 61:377-383

Koornneef M, Leon-Kloosterziel KM, Schwartz SH, Zeevaart JAD (1998) The genetic and molecular dissection of abscisic acid biosynthesis and signal transduction in Arabidopsis. Plant Physiol Biochem 36:83-89

Koster KL (1991) Glass formation and desiccation tolerance in seeds. Plant Physiol 96:302-304

Koster KL, Leopold AC (1988) Sugars and desiccation tolerance in seeds. Plant Physiol 88:829-832

Laby RJ, Kincaid MS, Kim D, Gibson SI (2000) The Arabidopsis sugar-insensitive mutants sis 4 and sis5 are defective in abscisic acid synthesis and response. Plant J 23:587-596

León P, Sheen J (2003) Sugar and hormone connections. Trends Plant Sci 8:110-116

Leprince O, Satour P, Ly-Vu B, Buitink J (2004) The role of sugars and hexose phophorylation in regulating the re-establishment of desiccation tolerance in germinated radicles of Cucumis sativa and Medicago truncatula. Physiol Plant 122:200-209

Leung J, Merlot S, Giraudat J (1997) The Arabidopsis ABSCISIC ACID-INSENSITIVE2 (ABI2) and ABI1 genes encode homologous protein phosphatases $2 \mathrm{C}$ involved in abscisic acid signal transduction. Plant Cell 9:759-771

Li Y, Lee KK, Walsh S, Smith C Hadingham S, Sorefan K, Cawley G, Bevan MW (2006) Establishing glucose- and ABA-regulated transcription networks in Arabidopsis by microarray analysis and promoter classification using a relevance vector machine. Genome Res 16:414-427

Lopez-Molina L, Mongrand S, Chua NH (2001) A postgermination developmental arrest checkpoint is mediated by abscisic acid and requires the ABI5 transcription factor in Arabidopsis. Proc Natl Acad Sci USA 98:4782-4787

Lopez-Molina L, Mongrand S, McLachlin DT, Chait BT, Chua NH (2002) ABI5 acts downstream of ABI3 to execute an ABAdependent growth arrest during germination. Plant J 32:317-328

Lopez-Molina L, Mongrand S, Kioshita N, Chua NH (2003) AFP is a novel negative regulator of $\mathrm{ABA}$ signaling that promotes $\mathrm{ABI} 5$ protein degradation. Genes Dev 17:410-418

Loreti E, De Bellis L, Alpi A, Perata P (2001) Why and how do plant cells sense sugars? Ann Bot 88:803-812

Mazzella MA, Arana MV, Staneloni RJ, Perelman S, Rodriguez Batiller MJ, Muschietti J, Cerdán PD, Chen K, Sánchez RA, Zhu T, Chory J, Casal JJ (2005) Phytochrome control of the Arabidopsis transcriptome anticipates seedling exposure to light. Plant Cell 17:2507-2516

Moore B, Zhou L, Rolland F, Hall Q, Cheng WH, Liu YX, Hwang I, Jones T, Sheen J (2003) Role of the Arabidopsis glucose sensor HXK1 in nutrient, light, and hormonal signaling. Science 300:332-336

Nambara E, Keith K, McCourt P, Naito S (1995) A regulatory role for the $\mathrm{ABI} 3$ gene in the establishment of embryo maturation in Arabidopsis thaliana. Development 121:629-636

Nambara E, Hayama R, Tsuchiya Y, Nishimura M, Kawaide H, Kamiya Y, Naito S (2000) The role of ABI3 and FUS3 loci in Arabidopsis thaliana on phase transition from late embryo development to germination. Dev Biol 220:412-423

Nambara E, Suzuki M, Abrams S, McCarty DR, Kamiya Y, McCourt $P$ (2002) A screen for genes that function in abscisic acid signaling in Arabidopsis thaliana. Genetics 161:1247-1255 
Niu X, Helentjaris T, Bate NJ (2002) Maize ABI4 binds Coupling Element 1 in abscisic acid and sugar response genes. Plant Cell $14: 2565-2575$

Ooms JJJ, Leon-Kloosterziel KM, Bartels D, Koornneef M, Karssen CM (1993) Acquisition of desiccation tolerance and longevity in seeds of Arabidopsis thaliana. Plant Physiol 102:1185-1191

Parcy F, Valon C, Raynal M, Gaubier-Comella P, Delseny M, Giraudat J (1994) Regulation of gene expression programs during Arabidopsis seed development:Roles of the ABI3 locus and of endogenous abscisic acid. Plant Cell 6:1567-1582

Price J, Li TC, Kang SG, Na JK, Jang JC (2003) Mechanisms of glucose signaling during germination of Arabidopsis. Plant Physiol 132:1424-1438

Price J, Laxmi A, St. Martin SK, Jang JC (2004) Global transcription profiling reveals multiple sugar signal transduction mechanisms in Arabidopsis. Plant Cell 16:2128-2150

Robinson CK, Hill SA (1999) Altered resource allocation during seed development in Arabidopsis caused by the abi3 mutation. Plant Cell Environ 22:117-123

Rognoni S, Teng S, Arru L, Smeekens SCM, Perata P (2007) Sugar effects on early seedling development in Arabidopsis. Plant Growth Regul 52:217-228

Rohde A, Van Montagu M, Boerjan W (1999) The ABSCISIC ACIDINSENSITIVE3 (ABI3) gene is expressed during vegetative quiescence processes in Arabidopsis. Plant Cell Environ 22: 261-270

Rohde A, Kurup S, Holdsworth M (2000) ABI3 emerges from the seed. Trends Plant Sci 5:418-419

Rolland F, Baena-Gonzalez E, Sheen J (2006) Sugar sensing and signalling in plants, conserved and novel mechanisms. Annu Rev Plant Biol 57:675-709

Rook F, Corke F, Card R, Munz G, Smith C, Bevan MW (2001) Impaired sucrose-induction mutants reveal the modulation of sugar-induced starch biosynthetic gene expression by abscisic acid signalling. Plant $\mathrm{J}$ 26:421-433

Rook F, Hadingham SA, Li Y, Bevan MW (2006) Sugar and ABA response pathways and the control of gene expression. Plant Cell Environ 29:426-434

Schuurmans JAMJ, van Dongen JT, Rutjens BPW, Boonman A, Pieterse CMJ, Borstlap AC (2003) Members of the aquaporin family in the developing pea seed coat include representatives of the PIP, TIP and NIP subfamilies. Plant Mol Biol 53:655-667
Smeekens S (2000) Sugar-induced signal transduction in plants. Annu Rev Plant Physiol Plant Mol Biol 51:49-81

Söderman EM, Brocard IM, Lynch TJ, Finkelstein RR (2000) Regulation and function of the Arabidopsis ABA-INSENSITIVE 4 gene in seed and abscisic acid response signaling networks. Plant Physiol 124:1752-1765

Suzuki M, Kao C-Y, Cocciolone S, McCarty DR (2001) Maize VP1 complements Arabidopsis abi3 and confers a novel ABA/auxin interaction in roots. Plant $\mathrm{J}$ 28:409-418

Trouverie J, Chateau-Joubert S, Thévenot C, Jacquemot M-P, Prioul J-L (2004) Regulation of vacuolar invertase by abscisic acid or glucose in leaves and roots of maize plantlets. Planta 219: 894-905

Tsukagoshi H, Saijo T, Shibata D, Morikami A, Nakamura K (2005) Analysis of a sugar response mutant of Arabidopsis identified a novel B3 domain protein that functions as an active repressor. Plant Physiol 138:675-685

Ullah H, Chen JG, Wang S, Jones AM (2002) Role of a heterotrimeric $\mathrm{G}$ protein in regulation of Arabidopsis seed germination. Plant Physiol 129:897-907

van Dijken AJH, Schluepmann H, Smeekens SCM (2004) Arabidopsis trehalose-6-phosphate synthase 1 is essential for normal vegetative growth and transition toflowering. Plant Physiol 135:969-977

Villadsen D, Smith S (2004) Identification of more than 200 glucoseresponsive Arabidopsis genes none of which responds to 3-Omethylglucose or 6-deoxyglucose. Plant Mol Biol 55:467-477

Yuan K, Wysocka-Diller J (2006) Phytohormone signalling pathways interact with sugars during seed germination and seedling development. J Exp Bot 57:3359-3367

Zeng Y, Kermode AR (2004) A gymnosperm ABI3 gene functions in a severe abscisic acid-insensitive mutant of Arabidopsis (abi3-6) to restore the wild-type phenotype and demonstrates a strong synergistic effect with sugar in the inhibition of post-germinative growth. Plant Mol Biol 56:731-746

Zhang X, Garreton V, Chua NH (2005) The AIP E3 ligase acts as a novel negative regulator of $\mathrm{ABA}$ signaling by promoting $\mathrm{ABI} 3$ degradation. Genes Dev 19:1532-1543

Zhou L, Jang JC, Jones TL, Sheen J (1998) Glucose and ethylene signal transduction crosstalk revealed by an Arabidopsis glucose-insensitive mutant. Proc Natl Acad Sci USA 95: 10294-10299 